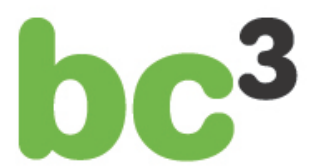

BASQUE CENTRE

FOR CLIMATE CHANGE

Klima Aldaketa Ikergai

\title{
Economic Assessment of Forest Ecosystem Services Losses: Cost of Policy Inaction
}

\author{
Aline Chiabai, Chiara Travisi, Anil Markandya, \\ Helen Ding, and Paulo Nunes
}

September 2010

BC3 WORKING PAPER SERIES

2010-13 
The Basque Centre for Climate Change (BC3) is a Research Centre based in the Basque Country, which aims at contributing to long-term research on the causes and consequences of Climate Change in order to foster the creation of knowledge in this multidisciplinary science.

The BC3 promotes a highly-qualified team of researchers with the primary objective of achieving excellence in research, training and dissemination. The Scientific Plan of BC3 is led by the Scientific Director, Prof. Anil Markandya.

The core research avenues are:

- $\quad$ Adaptation to and the impacts of climate change

- $\quad$ Measures to mitigate the amount of climate change experienced

- $\quad$ International Dimensions of Climate Policy

- $\quad$ Developing and supporting research that informs climate policy in the Basque Country

See www.bc3research.org for further details.

The BC3 Working Paper Series is available on the internet at

http://www.bc3research.org/working_papers/view.html

Enquiries (Regarding the BC3 Working Paper Series):

Roger Fouquet

Email: roger.fouquet@bc3research.org

The opinions expressed in this working paper do not necessarily reflect the position of Basque Centre for Climate Change (BC3) as a whole.

Note: If printed, please remember to print on both sides. Also, perhaps try two pages on one side. 


\title{
“Economic Assessment of Forest Ecosystem Services Losses: Cost of Policy Inaction”
}

\begin{abstract}
Aline Chiabai ${ }^{1}$, Chiara Travisi ${ }^{2}$, Anil Markandya ${ }^{3}$, Helen Ding ${ }^{4}$, and Paulo Nunes ${ }^{5}$
This paper presents a bottom-up methodological framework for estimating some of the key ecosystem services provided by forests biomes worldwide. We consider the provision of wood and non-wood forest products, recreation and passive use, and the forests' contribution to climate regulation in terms of carbon sequestration capacity. The valuation framework derives per hectare estimates by applying metaanalysis, value transfer and scaling up procedures in order to control for the existing heterogeneities across world regions and forest biomes. The first part of the study estimates stock values per hectare for each forest ecosystem service in the baseline year 2000 and in the year 2050. Carbon stocks represent, in general, the highest value per hectare, followed by provisioning services, passive use and recreational values. The second part provides an estimation of the welfare loss (or gain) associated with policy inaction in the period 2000-2050 leading to a change in the forest area. Welfare results are mixed and require a careful interpretation. In different world regions, no policy initiative can results in both gains and losses, which appear to be sensitive to the use of lower or upper bounds values per hectare.
\end{abstract}

Keywords: forest ecosystem goods and services; Millennium Ecosystem Assessment; valuetransfer, meta-analysis; market and non-market valuation

JEL Classification: Q23, Q26, Q51, Q54 and Q57

Cite as: A. Chiabai, C. M. Travisi, A. Markandya, H. Ding, and P.A.L.D Nunes (2010) Economic Assessment of Forest Ecosystem Services Losses: Cost of Policy Inaction. BC3 Working Paper Series 2010-13. Basque Centre for Climate Change (BC3). Bilbao, Spain.

\section{Acknowledgement}

This research was initially developed within the EU funded project COPI "Cost of Policy Inaction. The case of not meeting the 2010 biodiversity target”, aiming at valuing the total costs of no policy initiatives to modify the current paths of dynamics, by combining ecosystem service values and land use changes. The authors thank the whole COPI research team. The updated results presented here will contribute to the follow-up of the EU funded project on The Economics of Ecosystems and Biodiversity (TEEB).

\footnotetext{
${ }^{1}$ Basque Centre for Climate Change BC3, Spain.

${ }^{2}$ Fondazione Eni Enrico Mattei FEEM, Italy.

${ }^{3}$ Basque Centre for Climate Change BC3, Spain; University of Bath, UK.

${ }^{4}$ Fondazione Eni Enrico Mattei FEEM, Italy; School for Advanced Studies in Venice Foundation, University of Venice, Italy.

${ }^{5}$ Fondazione Eni Enrico Mattei FEEM, Italy; School for Advanced Studies in Venice Foundation, University of Venice, Italy.
} 


\section{Introduction}

\subsection{Where do we stand}

In recent years we have been witnessing a major debate on the potential effects of biodiversity loss, which was in part driven by unsustainable economic activities in most world regions. Biodiversity contributes to human well-being in two ways. On the one hand, it contributes directly by providing raw materials and contributing to health; on the other hand, it is indirectly related to human well-being through its essential role in supporting ecosystem functioning and supplying ecosystem goods and services to humans. These have entailed ethical questions on the role of humans in the stewardship of the planet's natural resources. As biodiversity decreases, what are we losing in terms of goods and services to humans? And what is the impact on the welfare and wellbeing of current and future population and societies?

Several studies have tried to provide economic estimates of the costs and benefits of land conversion and human activities inducing ecosystem services loss. However, the coverage of the available economic estimates of the costs of such a loss is partial, and the required research effort still massive. Amongst all ecosystems on earth, the present paper focuses on valuing the world's forest ecosystems services (ESs).

Forests not only provide timber but they also represent critically important habitats for the ecosystem services they supply (e.g. Miller et al., 1991; Mendelshon and Balick, 1995; Pearce, 1996, 1998, 1999). They regulate local and global climate, enhance soil retention and water quality, ameliorate water events, facilitate pollination, improve landscape aesthetics, provide habitats for a vast store of species, and enclose invaluable genetic information yet to be uncovered.

At the current alarming level of deforestation of approximately 13 million hectares per year (FAO, 2007), the loss of forest ecosystem services is expected to be serious. Evidence also suggests that ecosystems services loss could accelerate in the future as an effect of climate change (Pimm and Raven, 2000; Thomas et al., 2004). The international research community is committed to support policy action towards a sustainable use of forest resources worldwide, and the forest economic evaluation challenge has gradually reached the international policy agenda.

The stabilization of Green House Gas (GHG) emissions by forest conservation or prevention of deforestation - questions not originally included in the Kyoto Protocol - were addressed in COP13 in Bali on December 2007. Countries rich in forest resources, such as Brazil, asked for economic compensation for the ecosystem services that they can give to the planet by helping future conservation of 
millions of hectares of native woodland in the tropics. Besides, as loss of forest ecosystem services is mainly due to conversion of forests to agricultural land in South America and Asia, paying farmers for the environmental services they may conserve or provide is generating growing interest worldwide from policy makers to non-governmental and private decision-makers (FAO, 2007). As such policy initiatives are currently being debated, the availability of a worldwide perspective on forest service values is becoming pivotal and a common platform of analysis of forest services in needed.

Previous studies valuing biodiversity have mainly focused on single types of forest ecosystem services, either market and non-market, and forest types (e.g. Chomitz et al. 2005; Portela et al. 2008). The CBD report (2001) provided a comprehensive literature review of the market and non-market values of a vast array of forest services (from provisioning services to genetic information). Such estimates help us to understand the typologies and orders of magnitude of the services involved; however, they cannot be seen as representative of all forest areas, and they are not easily comparable at the global scale.

The total welfare contribution for ecosystem services has been estimated by Costanza et al. 1997 at USD33 trillion per year, but this approach has been criticized by economists for not being an incremental one (Toman 1998; Bockstael et al. 2000). There is little advantage in knowing the total value of an ecosystem unless there is a threat to eliminate it or a policy to reconstruct it in its entirety, which is rarely the case (Markandya et al., 2008). Regarding the valuation of non-market forest ecosystem services criticisms also exist with respect to the nature of the value estimates being used in the valuation, which tend to be very site specific, and transfer to other forests and locations are difficult or often not credible (Markandya et al., 2008).

\subsection{Moving forward}

Within the EU-funded project COPI "Cost of Policy Inaction: the case of not meeting the 2010 biodiversity target”, the authors have developed an original framework based on consolidated monetary valuation strategies able to tackle the different economic aspects of the provisioning, regulating and cultural ecosystem services provided by forests across the globe (see Figure 1). We consider the provision of wood and non-wood forest products (WFPs and NWFPs), cultural services (recreation, ecotourism and passive use), and the forests' contribution to climate regulation in terms of carbon sequestration capacity. We thus created a common bottom-up estimation platform to monetize the value of different forest ecosystems services, both market and non market ones, worldwide. Our approach looks at the global scale, but derives global estimations with meta-analysis, value transfer and scaling up procedures which are based on the larger as possible sets of regional and national data, in order to cover the highest variability in terms of geographical and socio-economic regions and forest biomes. To avoid 'adding up' 
problem and avoid potential biases, we do not estimate simple average values of forest ecosystem services, but we attempt to provide specific per hectare values for each world region and forest biome in the world. To do so, we rely on a thorough retrieval process that allows us to built, for each forest service analyzed, comprehensive databases gathering both estimates already available in the literature and row data to be used in the valuation procedure. Overall, the valuation methodological approach builds up on a three steps estimation process (see Figure 1).

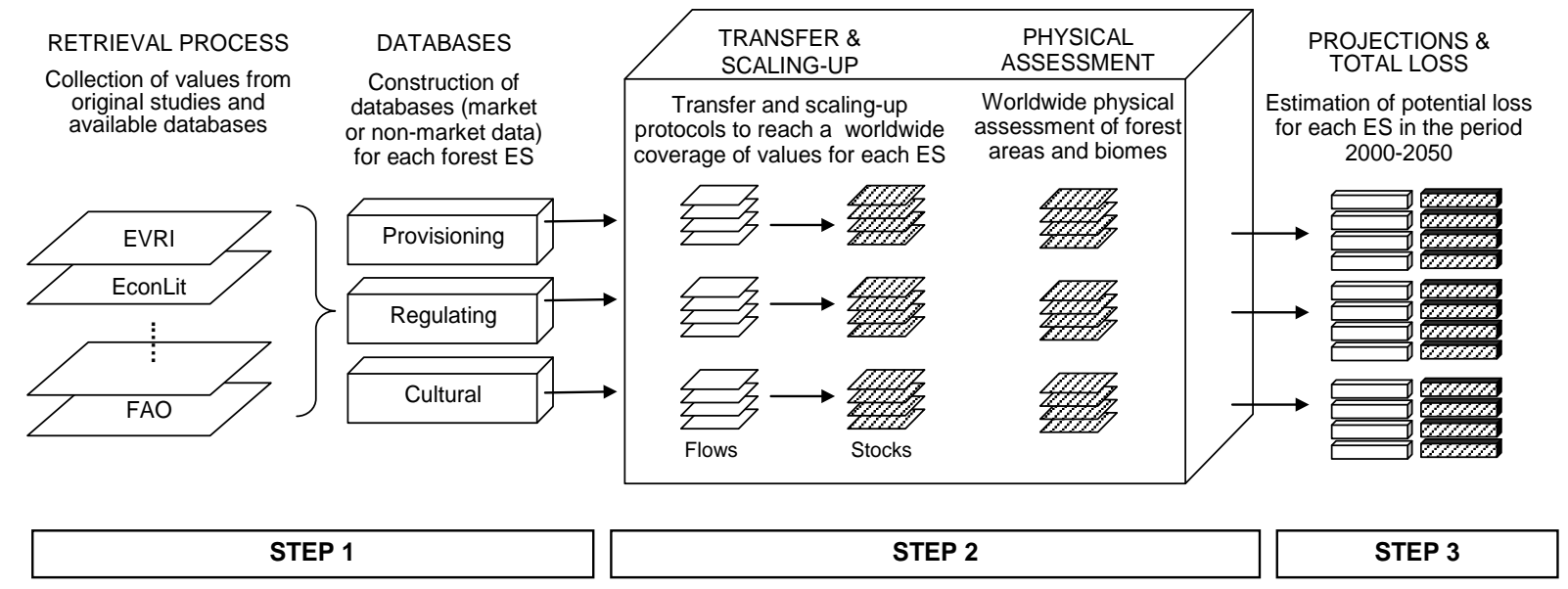

Figure 1. A schematic illustration of the overall methodological approach

Step 1 - Computation of annual flow values per hectare. For provisioning we provide an original estimation based on FAO data available at a much disaggregated geographical level (country level). For cultural and regulating forest services, to reach a worldwide coverage, we rely on meta-analysis, transfer or scaling up methods to unexplored world regions.

Step 2 - Computation of stock values per hectare. As we want to compare different forest services and look at the corresponding change in the natural capital stock between 2000 and 2050 we convert flows into stock values per hectare.

Step 3 - Projections of stock values per hectare from 2000 to 2050, and estimation of total welfare loss associated with the projected forest area changes.

All methodological details, merits and limitations, are presented and discussed in the following sections. In Section 2 we present the overall estimation platform, and describe forest ecosystem services, forest biomes, world regions and land use data. The specific estimation method employed for each forest service, and the main results, are detailed in Section 3. To conclude, Section 4 discusses the cost of policy inaction in year 2050, and offers some conclusive remarks, while discussing future challenges. 


\section{Valuing forest ecosystem services}

\subsection{A worldwide assessment of forest ecosystem services}

The forest ecosystems services considered in this study are selected according to data availability, world coverage, and relevance to decision making. This leads to the restricted set presented in Table 1. As defined by the MEA, provisioning services are the goods obtained from ecosystems and they include food, fiber, fresh water, and genetic resources. For forestry, we consider in particular wood and non-wood products (both plant and animal) extracted from natural or managed forested areas. Regulating services include benefits obtained from the regulation of ecosystem processes, including air quality regulation, climate regulation, water regulation, erosion regulation, pollination and natural hazard regulation. As for regulating services, above all, deforestation is responsible for a huge amount of carbon emissions. We thus estimate the role of forests in climate regulation as important carbon storage reservoirs. Cultural services are the nonmaterial benefits that people obtain from the ecosystem through aesthetic experience, reflection, recreation and spiritual enrichment. We refer to recreation/ecotourism and passive use of forests, these two dimensions being better covered by the economic valuation literature. The assessment provided is therefore not comprehensive of all forest ecosystem services, as not all instrumental values are covered. Besides, non-anthropocentric values (such as moral and spiritual values) - which should be taken into account in decision-making - do not lend themselves to this kind of quantification.

Table 1. List of forest Ecosystem Services addressed for the monetary estimation

\begin{tabular}{ll}
\hline MEA category & Ecosystem Services \\
\hline Provisioning & Food, fiber, fuel: wood and non wood products \\
Regulating & Climate regulation: carbon storage \\
Cultural & Recreation and ecotourism \\
& Passive use \\
\hline
\end{tabular}
Source: modified from MEA (2005).

Several valuation methods can be applied to estimate the monetary value attached to each different forest ecosystem services. By using the well-known notion of Total Economic Value (TEV), and depending on the nature of the good being valued, we can identify the best available valuation methodology to be employed for the monetary estimation of each ES of concern (see, e.g., Pearce and Moran, 1994). 
Broadly speaking, we employ market price data for the estimation of provisioning and regulating forest ESs while we rely on non-market (stated or revealed preference) valuation data to estimate forest cultural values. Greater uncertainty surrounds non-market values than the market values, but given the global perspective of this exercise, it is essential to rely on the full body of knowledge already available in the environmental economics literature in order to gather estimates that cover, for each service to be valued, the highest variability in terms of countries (world regions) and forest types (biomes). In this regard, a crucial role is played by the use of research synthesis techniques, such as meta-analysis and value transfer, within the non-market valuation.

For each forest ES, we first performed a thorough retrieval process and gather the wider as possible set of relevant market and non market data. In particular, for recreation and passive use values we were able to perform two formal meta-analyses. Second, we applied specific value transfer and scaling up protocols to adjust available values to new, unexplored, contexts and providing worldwide estimates. By means of multivariate meta-regressions, meta-analysis enables us to explain the variance of the available Willingness-To-Pay figures as a function of a set of statistically significant explanatory variables. The literature retrieval process comprised checking several economic and forest databases (among others EconLit, EVRI, FAO), reference chasing, and approaching key scholars in the field. This resulted in three different set of estimates, one for each MEA service category. Several of these values, however, do not provide usable estimates. Thus, the stock values actually employed represent a subsample of the whole body of the literature. Still they are intended to provide the maximum coverage of the variety of forest biomes that populate forest areas worldwide.

As for provisioning and regulating services, the estimation process is based on market data, actual and estimated, respectively. Data on forest products are drawn from the database on forests of the Food and Agriculture Organization (FAO) of the United Nations. Values are estimated with adjustments taking into account: product category or industrial sector; country of origin; forest biome; forest size designated to production; profitability of the forest sector. For carbon valuation, we refer to the WITCH model developed by FEEM ${ }^{6}$ (Bosetti et al, 2009; Bosetti et al, 2007), providing price ranges for different future scenarios and we combine this information with data on carbon capacity per forest type and country.

As we want to evaluate changes in forest stocks and in the related provisioning, regulating and cultural services they provide between 2000 and 2050, the estimation results employed for the transfer, scaling up and projection represent stock values. Flow values have thus been converted into stock values under the assumption that flows remain constant over time $t$ by using the perpetual revenue formula in

\footnotetext{
${ }^{6}$ Fondazione Eni Enrico Mattei, WITCH model version 2008. Available at: http://www.witchmodel.org/simulator.
} 
Eq.1, at the usual 3 percent discount rate, $i$, applied by the European Commission (see Gordon and Myron 1959) ${ }^{7}$.

Eq. $1 \quad V=\frac{V(t)}{i}$

Where $V$ is the stock value and $V(t)$ is the flow value over time $t$.

\subsection{Forest biomes, world regions, forest areas and land-use changes from 2000 to 2050}

Projections of forest areas are based on IMAGE-GLOBIO ${ }^{8}$ model of changes in land use and ecosystem services over the period 2000-2050. The classification of forest biomes and world regions - as proposed by the GLOBIO model framework (Alkemade et al., 2006) employed by COPI - distinguishes 6 main different forest biomes ${ }^{9}$ distributed across 12 world regions (see Table 2). COPI provides estimates of the spatial coverage and distribution of each forest biomes for 2000 and 2050 as described by the OECD Baseline Scenario (see Bakkes and Bosh, 2008), taking into account different drivers and pressures. Changes of forests over time are mainly driven by land use changes (see Table 3). In particular, agricultural land-use changes (i.e. forest areas converted into farmland) and forest management (i.e. natural forests versus managed forest) remain the greatest driving forces influencing forestry productivity. In this paper only two land uses of forests are considered, namely "natural forest” and "managed forest”. The former includes pristine forests as well as relatively untouched forests almost devoid of human

\footnotetext{
${ }^{7}$ The choice of the appropriate discount rate is much debated in the scientific and policy community, especially for valuing losses of natural resources, involving long-time impacts, intergenerational issues and latent non-marginal impacts. Discount rates between $0 \%$ and 3\% are usually used (Hope, 2006). According to Weitzman (2001), a declining discount rate should be used for long term natural resource projects in order to account for intergenerational equity, while allowing for economic efficiency (Portney and Weyant, 1999). Evans (2004) refers to 3 percent discount rate for the near future up to 25 years, 2 percent discount rate for the medium future, 26 to 75 years, and 1 percent discount rate for the distant future, 76 to 100 years. In our study we make the conservative choice of using the 3 percent discount rate as both market and non-market values are included in the assessment, and discounting timber value is less contentious than passive and recreation values.

${ }^{8}$ IMAGE 2.4 (Integrated Model to Assess the Global Environment) (MNP, Bouwman et al., 2006) is an ecologicalenvironmental model that simulates the impacts of human activities on the natural resources, taking into account the interactions between economic, demographic, technological, social and political factors (http://www.pbl.nl/en/themasites/image/index.html). Direct and indirect pressure on natural resources is considered, including industry, transport, agriculture, forestry and housing. Results of this model are used as input to another model, GLOBIO3 (Alkemade et al., 2006), which is used to assess the impacts of different stressors on biodiversity and natural ecosystems (http://www.globio.info/). The pressures considered in GLOBIO 3 include land-cover change (agriculture, forestry, built-up area), land-use intensity, atmospheric nitrogen deposition, infrastructure development, fragmentation and climate change. The model is linked to IMAGE 2.4 through the changes in land use, vegetations zones and climate change.

${ }^{9}$ The forest biomes analyzed by GLOBIO3 are boreal, tropical, warm-mixed, cool coniferous, temperate mixed and temperate deciduous forests.
} 
imprints ${ }^{10}$, whereas the latter refers to the forest areas partially designated to extensive cultivation, wood production. The valuation of forest ecosystem services in this paper refers as much as possible to these forest varieties (biomes and forest management type) and world regions.

Table 2 World regions used in GLOBIO and COPI ${ }^{11}$

\begin{tabular}{ll}
\hline World regions & Description \\
\hline NAM & North America \\
EUR & OECD Europe \\
JPK & OECD Asia (Japan \& Korea) \\
ANZ & OECD Pacific (Australia \& New Zealand) \\
BRA & Brasil \\
RUS & Russia \& Caucasus \\
SOA & South Asia (and India) \\
CHN & China Region \\
OAS & Other Asia \\
ECA & Eastern Europe \& Central Asia \\
OLC & Other Latin America \& Caribbean \\
AFR & Africa \\
\hline \multicolumn{2}{c}{ Source: Braat and Ten Brink, 2008. }
\end{tabular}

The projection begins with some important assumptions for constructing the baseline, according to which many aspects of today's world will remain the same for the next 50 years, evolving along the same lines as today (Braat and Ten Brink, 2008). The major assumptions are summarized in Table 3. The model projects an increase in population and income which influences in turn diet, mobility demand and consumption preferences expected to increase in the same way as in the past. In this context, the baseline scenario serves as a benchmark to identify the need for policy action in specific areas detected as particularly vulnerable, and to assess the impact of new strategies to protect forest areas and related forest ecosystem services (Braat and Ten Brink, 2008). The COPI assessment presented in this paper is therefore defined as the "economic damage costs associated with a loss of EGSs due to loss of forest area, occurring in the absence of additional policy or policy revision” (business-as-usual scenario) (Braat and Ten Brink, 2008). The analysis does not include wider social costs related to forest land converted into other land uses, such as urban (infrastructures) or agricultural land.

A dominating uncertainty around these assumptions is the rate of increase in economic activities. From the discussion of key variants to the economic baseline (OECD, 2008 and Bakkes \& Bosch, 2008) it is clear that the baseline is conservative. In particular, if the period around the year 2000 had been given more weight in constructing the baseline, as opposed to equally weighting the whole period from 1980 to2000 period, GDP per capita levels in countries like Brazil, Russia India and China would have been

\footnotetext{
${ }^{10}$ Pristine areas are disappearing and represent only a small percentage of total forests.

${ }^{11}$ See Table A6 in the Annex for countries broken down.
} 
projected much higher. Historic trends are not the only ingredient for the economic baseline, but they constitute an important point of choice. Although the modeling for this study is more nuanced than assuming a fixed relation between GDP and pressures on ecosystem services and biodiversity, it should be noted that the uncertainty in the baseline leans to the side of more pressures. This by itself makes it more probable that the COPI assessment in this study errs on the side of underestimation, rather than overestimation.

Another limitation of the IMAGE-GLOBIO model is that it does not allow for a feedback analysis (Braat and Ten Brick, 2008), according to which the loss of ecosystem services should impact the GDP growth. Instead the GDP is expected to grow independently of the loss of natural capital. A final limitation is that the model does not account for critical thresholds in losses of ecosystems, which should lead to exponential damages.

Table 3. Major assumptions for forest change projections

\begin{tabular}{|c|c|}
\hline $\begin{array}{l}\text { Criteria under } \\
\text { consideration }\end{array}$ & Major assumptions \\
\hline \multicolumn{2}{|r|}{ Socio-economic and environmental criteria } \\
\hline Population & $\begin{array}{l}\text { Projected world population will be stabilized at around } 9.1 \text { billion inhabitants by } 2050 \\
\text { (UN, 2005). }\end{array}$ \\
\hline GDP & Annual growth rate at 2.8\% between 2005 and 2050. \\
\hline Biodiversity & It is assumed that increased GDP will increase the pressures on biodiversity. \\
\hline Energy consumption & Increase from 280 EJ to 2000 to 470 EJ in 2030, and ca 600 EJ in 2050. \\
\hline $\begin{array}{l}\text { Agricultural } \\
\text { production }\end{array}$ & $\begin{array}{l}\text { The production will need to increase by more than } 50 \% \text { in order to feed a population } \\
\text { more than } 27 \% \text { larger and roughly } 83 \% \text { wealthier than today's, with an extended } 10 \% \\
\text { of agricultural area and continuous evolution of agricultural productivity. }\end{array}$ \\
\hline \multicolumn{2}{|r|}{ Major policy implications } \\
\hline $\begin{array}{l}\text { The "protected area" } \\
\text { policy }\end{array}$ & The implementation will not substantially change current trends. \\
\hline Climate change policy & $\begin{array}{l}\text { No post-Kyoto regime other than the policies in place and instrumented by 2005; the } \\
\text { existing trading scheme for emission credits is included. }\end{array}$ \\
\hline $\begin{array}{l}\text { EU common fisheries } \\
\text { policy and equivalent } \\
\text { policies in other world } \\
\text { region }\end{array}$ & No significant changes in the current policy implementation. \\
\hline $\begin{array}{l}\text { Policy for biodiversity } \\
\text { conservation }\end{array}$ & $\begin{array}{l}\text { The policies towards conservation of forests and sustainable use of biodiversity exist } \\
\text { but remain lack of enforceability and ineffective. }\end{array}$ \\
\hline
\end{tabular}

Source: Braat and Ten Brink, 2008. 


\subsubsection{Results}

The model provides projections of forest land-use changes across various forest biomes and world regions between 2000 and 2050, under the assumption that no additional policy or policy revision is adopted. The results of the projection are presented in Table 4, where the world's forest area is found to decrease by a further 117 million hectares by 2050 (corresponding to 3.2\% of current worldwide forest area). The highest absolute loss is expected to occur in Russia (about 47 million hectares) and in Brazil (41 million hectares). As regards forest biomes, tropical forests reveal the highest absolute loss (most of which is registered in Brazil), followed by boreal forests (mainly in Russia).

Russian boreal forests, known as the Taiga, correspond to the largest forested area in the world, greater than the Amazon forest (see Table A1 in the Annex). Among the different eco-regions of the boreal forests in Russia, there is the Eastern-Siberian Taiga which is the greatest untouched boreal forest on the earth. The deforestation taking place in the Russian forests is around $20,000 \mathrm{~km}^{2}$ per year, which is comparable to the deforestation rate in the Amazon forest of Brazil. This high rate is related to timber extraction and forestry activities, intensified by the demand for timber in China and Southeast Asia and demand for pulp in Europe. Other stressors for the Russian boreal forests are represented by illegal timber extraction which does not follow sustainable practices, and forest fires which particularly threaten the Siberian forests.

As regards deforestation in the Amazon forest of Brazil, this is historically associated with the unsustainable use of land for commercial pasture, exploitation of timber and other forest products. The major pressure is represented by cattle ranching and small-scale subsistence agriculture, while large-scale agriculture is more widespread outside the rainforest. Deforestation that is currently taking place in the tropical forests is related to the economic growth which creates a big pressure on the exploitation of forest resources. The impact of deforestation in tropical forests is more dramatic than for boreal and temperate forests. This is because boreal and temperate forests are more adapted to rapid regeneration (they regenerated between glaciations periods), and because their biodiversity level is much lower than that in tropical forests. These latter need much more time to regenerate, once deforested, and their loss entails a significant loss in terms of biological species. This conflict between economic development and exploitation of forest resources in developing countries can be solved only by undertaking sustainable forest management plans.

From Table 4, we can observe an obvious trend of land-use changes in the next 50 years in which a large decline of natural forests will be substituted by an increase in managed forests. This can be seen also by analyzing the share of managed forest compared to natural forest in the two tables in the Annex (Table 
A1 and A2), according to which the percent of forest designated to plantation is expected to increase by 2050 for almost all the world regions, while the proportion of natural forest is decreasing.

In some world regions, the depletion of natural forests in absolute terms is much lower than the corresponding increase of managed forests, which leads to an increase in the total forest area in these regions by 2050 (e.g. Europe). In the OECD Asia region (Japan \& Korea, JPK) an increase is expected in both natural and managed forests. In all the other regions, instead, the loss of natural forest areas is much higher than the expected increase in managed forests, which leads to a total loss of hectares. The increase in managed forests, even if expected to be quite high in percentage terms (62\% increase on worldwide forests by 2050), cannot therefore compensate the loss of natural areas (8\% decrease worldwide by 2050). In addition, the increase in managed forest area is generally accompanied by a rapid deterioration of the quality of the forests. European forests, in particular, are endangered by air pollution, extreme weather events, droughts and infestations. In developing countries major pressures are represented by the overexploitation of fuelwood, overgrazing, fires and pests, which lead to gradual degradation of forest areas.

It can be noticed that a dramatic depletion of natural forests is observed in the Eastern European and Central Asia (ECA) (35\% loss compared with year 2000), where it is estimated that 100,000 hectares of forests were lost in the last 20 years because of forest damage (FAO, 2007). 
Table 4. Projected forest area changes in terms of forest biome and land use type across world regions 2000-2050 (1,000 hectare)

\begin{tabular}{|c|c|c|c|c|c|c|c|c|c|c|c|c|c|}
\hline $\begin{array}{l}\text { Forest biome } \\
\text { and landuse }\end{array}$ & NAM & EUR & JPK & ANZ & BRA & RUS & SOA & CHN & OAS & ECA & OLC & AFR & Total \\
\hline Boreal & -4031 & 1867 & 27 & -116 & 0 & -35674 & -760 & 212 & -1 & -531 & -723 & 0 - & 39,731 \\
\hline natural & -24301 & -6425 & -590 & -125 & 0 & -36080 & -1400 & -4526 & -2 & -1238 & -836 & $0-$ & 75,523 \\
\hline managed & 20270 & 8293 & 618 & 8 & 0 & 406 & 639 & 4738 & 0 & 707 & 112 & 0 & 35,791 \\
\hline Tropical & 219 & 0 & 4 & -24 & -36214 & 0 & -39 & 19 & -6288 & 0 & 392 & $-3282-$ & 45,579 \\
\hline natural & -10 & 0 & 6 & -225 & -41638 & 0 & -654 & -236 & -16503 & 0 & -2905 & $-13824-$ & 75,989 \\
\hline managed & 229 & 0 & -1 & 201 & 5058 & 0 & 615 & 254 & 10215 & 0 & 3296 & 10542 & 30,409 \\
\hline Warm mixed & 17 & 282 & 102 & -1270 & -4476 & -1 & -3730 & 243 & -705 & 0 & -4194 & -8187 & 21,553 \\
\hline natural & -13248 & -1335 & 207 & -1935 & -5146 & -1 & -10089 & -7811 & -2018 & 0 & -4745 & $-10181-$ & 56,303 \\
\hline managed & 13265 & 1617 & -105 & 665 & 1036 & 0 & 6359 & 8053 & 1313 & 0 & 552 & 1994 & 34,750 \\
\hline Temp. mixed & 303 & 1870 & 1666 & -147 & 0 & -6252 & -427 & 12 & 0 & -5584 & -115 & 0 - & 8,674 \\
\hline natural & -14299 & -8620 & -864 & -167 & 0 & -6231 & -1008 & -759 & 0 & -5254 & -147 & $0-$ & 37,347 \\
\hline managed & 14602 & 10489 & 2530 & 20 & 0 & -21 & 580 & 771 & 0 & -331 & 32 & 0 & 28,673 \\
\hline Cool coniferous & -1252 & -781 & 57 & 0 & $\mathbf{0}$ & -4621 & -437 & -5 & $\mathbf{0}$ & -216 & 0 & 0 - & 7,254 \\
\hline natural & -5257 & -5288 & -981 & 0 & 0 & -4627 & -869 & -1078 & 0 & -671 & 0 & $0-$ & 18,772 \\
\hline managed & 4005 & 4507 & 1038 & 0 & 0 & 7 & 432 & 1073 & 0 & 455 & 0 & 0 & 11,517 \\
\hline Temp. deciduous & 200 & 5673 & 1366 & -280 & 0 & -426 & -613 & 92 & -25 & -423 & -19 & -146 & 5,400 \\
\hline natural & -8342 & -4056 & 2424 & -449 & 0 & -422 & -4092 & -5043 & -83 & -401 & -40 & $-153-$ & 20,657 \\
\hline managed & 8542 & 9729 & -1058 & 169 & 0 & -4 & 3479 & 5135 & 58 & -21 & 21 & 6 & 26,057 \\
\hline Total & -4545 & 8912 & 3224 & -1836 & -40690 & -46974 & -6007 & 572 & -7019 & -6754 & -4659 & $-11616-$ & 117,392 \\
\hline $\begin{array}{c}\% \Delta(2000 \text { base }) \\
\text { TOTAL }\end{array}$ & $-0.5 \%$ & $3.8 \%$ & $7.0 \%$ & $-3.3 \%$ & $-10.5 \%$ & $-4.2 \%$ & $-17.3 \%$ & $0.2 \%$ & $-3.4 \%$ & $-26.6 \%$ & $-1.6 \%$ & $-7.1 \%$ & $-3.2 \%$ \\
\hline $\begin{array}{c}\% \Delta(2000 \text { base }) \\
\text { NATURAL }\end{array}$ & $-8.5 \%$ & $-15.2 \%$ & $0.5 \%$ & $-5.4 \%$ & $-12.2 \%$ & $-4.4 \%$ & $-70.5 \%$ & $-8.6 \%$ & $-9.8 \%$ & $-34.7 \%$ & $-3.1 \%$ & $-15.3 \%$ & $-8.4 \%$ \\
\hline $\begin{array}{c}\% \Delta(2000 \text { base }) \\
\text { MANAGED }\end{array}$ & $73.7 \%$ & $53.9 \%$ & $49.5 \%$ & $66.3 \%$ & $117.7 \%$ & $0.8 \%$ & $133.1 \%$ & $92.7 \%$ & $74.5 \%$ & $22.7 \%$ & $53.1 \%$ & $180.8 \%$ & $61.6 \%$ \\
\hline
\end{tabular}

\section{Estimation approach: from site-specific values to worldwide estimates}

\subsection{Provisioning services}

\subsubsection{Methodology}

Forest provisioning services have been classified into two main categories, following the FAO recommendation: wood forest products (WFPs) and non-wood forest products (NWFPs) (FAO 1999). Wood forest products include industrial wood, wood fuel, small woods and other manufactured wood products. In our study we refer to seven product categories, as identified in FAOSTAT ${ }^{12}$, representing different industrial sectors: industrial roundwood, wood pulp, recovered paper, sawnwood, wood-based panels, paper and paper board, and wood fuel (see Table 5). Non-wood forest products are defined as "all

\footnotetext{
${ }^{12}$ http://faostat.fao.org/
} 
goods of biological origin, as well as services, derived from forest or any land under similar use, and exclude wood in all its forms" (FAO, 1999). They can be gathered from the wild or produced in forest plantations, agro-forestry land or from trees outside the forest. NWFPs include for example food and food additives (e.g. fruits, nuts, mushrooms, herbs), fibres (raw material for utensils and construction), resins, plant and animal products used as medicinal or cosmetics (Table 5).

Table 5. Provisioning services provided by forest ecosystems

\begin{tabular}{|c|c|c|}
\hline \multirow{2}{*}{ Wood forest products (WFPs) } & \multicolumn{2}{|c|}{ Non-wood forest products (NWFPs) } \\
\hline & Plant products & Animal products \\
\hline $\begin{array}{ll}\text { - } & \text { Industrial Roundwood } \\
\text { - } & \text { Recod pulp } \\
\text { - } & \text { Sawnwored paper } \\
\text { - } & \text { Wood-based panels } \\
\text { - } & \text { Paper and paper board } \\
\text { - } & \text { Wood fuel }\end{array}$ & $\begin{array}{ll}\text { - } & \text { Food } \\
\text { - } & \text { Fodder } \\
& \text { Raw material for } \\
& \text { prodicine and aromatic } \\
\text { - } & \text { Raw material for } \\
& \text { colorants and dyes } \\
\text { - } & \text { Raw material for } \\
& \text { utensils, crafts \& } \\
\text { - } & \text { Onstruction } \\
\text { - } & \text { Exudates } \\
\text { - } & \text { Other plant products }\end{array}$ & $\begin{array}{ll}\text { - } & \text { Living animals } \\
\text { - } & \text { Hides, skins and trophies } \\
\text { - } & \text { Wild honey and beeswax } \\
\text { - } & \text { Bush meat } \\
\text { - } & \text { Other edible animal } \\
& \text { products }\end{array}$ \\
\hline
\end{tabular}

Sources: FAOSTAT and FAO/FRA 2005.

The economic value of forest provisioning services is a direct use value and it is estimated using market data based on current quantities and prices available from Food and Agriculture Organization (FAO) of the United Nations database on forests for year 2005 as specified below ${ }^{13}$.

\section{Wood Forest Products}

For WFPs, in the absence of data about prices of forest stocks, one commonly used method is to estimate the sum of the discounted future earnings flows from timber production (net present value method); however the data needed for this calculation are not easy to obtain, especially when they have to be consistent and cover all regions. The theoretically correct measure for estimating the flows is the stumpage price, which is the price paid by the logging companies to the owners of the forests for getting the right of harvesting standing timber. It can be estimated by deducting the unit cost of logging and transportation from trading price of timber product, i.e. the felling price in the market.

\footnotetext{
${ }^{13}$ http://faostat.fao.org/site/626/default.aspx\#ancor/
} 
In the present study, the methodological approach builds up on a three-step estimation process: (i) computation of annual net value (NV) per hectare (flow), (ii) computation of the net present value (NPV) per hectare (stock), and (iii) projections of stock values to year 2050. Projections of stock values are estimated in order to compute the total welfare loss due to policy inaction (see Section 4).

The first step consists of calculating first the total value of all forest products for each country, taking into account export values, domestic production and export quantities for year 2005, available at country level from FAOSTAT. Results are reported in Table A3 in the Annex (total values are summedup at world region level for the purpose of the study). Subsequently, total values, as calculated above, are adjusted according to forest net rents, also available at country level (Bolt et al, 2002) ${ }^{14}$, in order to get a net value (NV) of wood forest products, which approximate the stumpage price (Eq.2):

Eq. $2 N V_{i, j}=\left[E V_{i, j} \times \frac{P q_{i, j}}{E q_{i, j}}\right] \times r_{i}$

Where $N V_{i, j}$ represents the net value of WFPs by country $i$ and product $j, E V_{i, j}$ is the export value, $P q_{i, j}$ is the domestic production quantity, $E q_{i, j}$ denotes the export quantity, and $r$ the rent rate.

The net values estimated in Eq.2 are computed in US\$2005. For simplicity of calculations, we assume that the net values for year 2005 are constant over time ${ }^{15}$, which allows us to consider them as an annual flow of WFPs. The second estimation step consists of converting this annual flow into a net present value NPV (stock values) using the formula for the present value of a perpetual annuity, as follows:

Eq. $3 \quad N P V_{i, j}=\frac{N V_{i, j}}{d}$

Where $N P V_{i, j}$ is the net present value (or stock value), $N V_{i, j}$ is the net value (or flow value) and $d$ is the discount rate.

In order to compute an average value per hectare, NVs and NPVs of all forest products are firstly aggregated by world region, and then divided by the forest area designated to plantation in each region

\footnotetext{
${ }^{14}$ The forest net rents of world countries are taken from World Bank database, available online at: http://tahoe-iswalking-on.blogspot.com/2010/01/world-banks-ans-adjusted-net-saving.html.

${ }^{15}$ This is confirmed by an analysis we have performed on the World Bank time series data (http://tahoe-is-walkingon.blogspot.com/2010/01/world-banks-ans-adjusted-net-saving.html), according to which the average prices for timber in the last 30 years (1971-2002) appears to follow a constant trend.
} 
and forest biome in the baseline year (see Eq. 4) ${ }^{16}$. The main assumption behind is that each hectare of managed forest has the same productivity and profitability, regardless the forest type and the tree species.

Eq. $4 \quad A V_{w r, f}=\frac{\sum_{i \in w r} \sum_{j} N P V_{i . j}}{\sum_{i} S_{w r, f}}$

$A V_{w r, f}$ represents the NPV of WFPs per hectare by world region wr and forest biome $f$, and $S_{w r, f}$ is the forest area designated to plantation.

The third step consists of projecting the net stock values per hectare for year 2050. For this purpose, we refer to two studies (Clark, 2001; Hoover and Preston, 2006) that analyze long-term historical data. Clark (2001) offers a theoretical analysis and an empirical examination of wood prices, based on aggregated global wood market data over the last three decades. Hoover and Preston (2006) analyze trends of Indiana (USA) forest products prices using statistical data from 1957 to 2005. Although different in the spatial scale of the analyses, both papers lead to a similar conclusion: there is no evidence of increase in real prices for wood in the long term. This means that that no global wood shortage is predicted, a result that can be explained by the technological development leading to an increase in resource productivity (less wood required in the production process and enhanced wood supply). This statement is also corroborated by an analysis on the World Bank time series data ${ }^{17}$ providing estimates of the average prices for total produced round wood (Bolt et al. 2002), according to which the trend in real prices remained relatively constant in the 30-years period 1971-2006. We therefore assume that real prices of wood products will remain stable in the long run, while allowing different prices to exist across countries and continents.

\section{Non-Wood Forest Products}

As regards NWFPs, they are playing a crucial role especially in developing countries, where they contribute to poverty alleviation and local development. They are particularly important for indigenous people who practice traditional gathering of NWFPs used as foods and medicines (FAO, 1995). Despite their relevance, however, a systematic monitoring and evaluation of NWFPs products is still missing in many countries (Donoghue et al, 2004), leading to difficulties in the estimation procedure. Most of the current knowledge about NWFPs comes from traditional uses made by indigenous people. More information is therefore required to evaluate the economic relevance of these products, in terms of

\footnotetext{
${ }^{16}$ In this study, following Braat et al. (2008), productive forest areas are referred to as "managed forest".

${ }^{17}$ World Bank database, available online at: http://tahoe-is-walking-on.blogspot.com/2010/01/world-banks-ansadjusted-net-saving.html.
} 
quantities, economic values (prices) and product status. Notwithstanding this difficulty, we decided to include NWFPs in our analysis, taking into account the available information from FAO (FRA, 2005) for year 2005. The economic values of NWFPs are estimated based on the export values of the total removals at country level, when available, and then aggregated for each COPI region. These values represent flows of NWFPs and have been then translated into stock values or NPV. Finally, average values per hectare per region are computed by dividing the total value of NWFP by the total hectares of forests in the baseline year 2005. It was not possible to project these values in future scenarios due to the lack of statistical data on price trends in this context. The contribution of NWFPs to the overall economic value provided by forest provisioning services is, however, expected to be quite low if compared with WFPs. Therefore the inclusion of these products in the analysis, even if underestimated, will probably not affect significantly the overall valuation of provisioning services.

\section{Limitations}

There are several limitations and weaknesses surrounding the methodology used for estimating WFPs and NWFPs. The first regards the assumption that each forest hectare has the same productivity for the computation of an average value per hectare of WFPs. Productivity of WFPs is instead expected to vary according to the forest type and the tree species (within the same forest type). It was nevertheless not possible to take into account this dimension in a worldwide study, mainly because of lack of data. The results presented are therefore able to capture only the geographical variation at national level, as values are constructed using a bottom-up approach at country level. They are not capturing, instead, the difference in value due to forest type and tree species, as well as differences at sub-national level due to socio-economic factors.

Another limitation regards the projection of stock values to year 2050, which are expected to remain constant, compared to year 2005. Even if the overall trend is expected to remain constant, there might be geographical variations, as confirmed by an analysis of the World Bank time series data about prices of round wood (Bolt et al. 2002). These variations have not been considered in our study, and it has been assumed that productivity will remain constant over time at country level.

As regards NWFPs, the estimation is constrained by lack of data, as already specified. It must be said, however, that the benefits of NWFPs are not totally captured by the economic value, because a small amount of population are making use of them (mostly indigenous people), which results in small economic values per hectare. Their importance could be better evaluated considering the value of NWFPs in terms of contribution to the household incomes (Kramer et al, 1995; Bahuguna, 2000; Cavendish, 
1999). These products are important for supporting local community income and for alleviating poverty, especially in developing countries.

\subsubsection{Results}

Estimates of NPVs (stocks) per hectare, for both WFPs and NWFPs, are provided in Table 6, per world region and forest biome. The values are reported in US\$ 2005. Differences in NPVs per hectare result from the combined effect of total production values by forest products, distribution of forest area across regions and incidence of forest area designated to plantation in each region.

The contribution of NWFPs appears to be quite small if compared to WFPs, with percentages in developed countries ranging from $0.02 \%$ for NAM to $1.9 \%$ for EUR, and in developing countries from $0.02 \%$ for RUS to $1.2 \%$ for OAS (see Table A3 in the Annex). Despite their small contribution, specific attention has been recently given to NWFPs, since they can play a significant role in strengthening local economies and in the conservation of ecological systems by adopting sustainable forest management practices.

In tropical forests (Table 6) the highest NPVs are registered in AFR, OAS, BRA and OLC regions. As regards specifically Africa, the reason for these high values seems to be related to the fact that the last decades have seen a large expansion of forestry with high yields and large-scale plantations. The expansion of planted forests, especially tropical forests (See Figure 2) over the last years is resulted of a combination of many factors, including a high exploitation of natural forests, an increasing demand for wood products engendered by population growth and urbanization, an intensification of industrialization and an increase in exports of timber and wood forest products (Chamshama and Nwonwu, 2004). At the same time natural forests are characterized instead by low growth rates, while afforestation rates are much lower than the corresponding loss of indigenous forests. As regards the financial returns of planted forests, they depend heavily on the ownership of the plantations, i.e. whether public or private owned forests. Profitability in public forests is quite low due to inefficiencies in management and low productivity levels. The private sector, on the contrary, especially in South Africa, is characterized by high profitability and viable financial returns. Between 1980 and 2000, the forest industry in South Africa presented a very high increase in the value of sales (1460\%) (Chamshama and Nwonwu, 2004). These factors might explain the high net value per hectare of forest stocks estimated for plantation in Africa. The forest products which contribute more to the high values are specifically wood fuels, followed by industrial round wood.

In the boreal and warm-mixed forest biomes (see Figure 3), ANZ shows the highest NPV per hectare. Not surprisingly, in Australia, the forest industry adds significantly to the national economy, 
contributing to around $0.6 \%$ to the Gross Domestic Product and 6.7\% to the manufacturing output (data $2009^{18}$ ). The forestry sector in Australia is characterized by high quality products and competitive supporting infrastructures, which attract investment opportunities in the sector, with strategies put in place to endorse the export segment.

The results obtained for the average NPV per hectare might be slightly overestimated because in our framework we assume that harvesting is taking place only in managed forests, while some portions of natural areas that might be exploited for timber production are excluded from the present computation due to a lack of official statistics on logging in natural forests. In particular, problems in association with illegal logging ${ }^{19}$ are severe in many countries (Amazon forests, Central Africa, Southeast Asia and Russia), which makes it difficult to calculate the correct forest areas being exploited for timber production. It is estimated that around $50 \%$ of timber from tropical forests and $20 \%$ of timber from boreal forests come from illegal activities (Taiga Rescue Network, Sweden ${ }^{20}$ ).

Table 6. NPV per hectare of WFPs by world region and forest biome, stock values (2005US\$/ha)

\begin{tabular}{lccrrrr}
\hline $\begin{array}{l}\text { World } \\
\text { Region }\end{array}$ & Boreal & Tropical & $\begin{array}{r}\text { Warm- } \\
\text { mixed }\end{array}$ & $\begin{array}{r}\text { Temperate } \\
\text { mixed }\end{array}$ & $\begin{array}{r}\text { Cool } \\
\text { coniferous }\end{array}$ & $\begin{array}{r}\text { Temperate } \\
\text { deciduous }\end{array}$ \\
\hline NAM & 166,987 & 1,612 & 39,882 & 68,561 & 35,612 & 35,056 \\
EUR & 27,734 & - & 1,543 & 11,137 & 12,100 & 15,996 \\
JPK & 86,895 & 271 & 5,721 & 106,366 & 168,131 & 71,228 \\
ANZ & 199,179 & 22,710 & 93,262 & 7,519 & - & 28,407 \\
BRA & - & 57,124 & 15,224 & - & - & - \\
RUS & 10,793 & - & 15 & 8,270 & 1,487 & 555 \\
SOA & 98,651 & 8,345 & 62,113 & 6,294 & 41,918 & 26,108 \\
CHN & 128,005 & 2,408 & 52,917 & 6,261 & 24,444 & 48,639 \\
OAS & 190,036 & 126,590 & 9,948 & - & - & 263 \\
ECA & 15,785 & - & - & 17,026 & 9,702 & 1,321 \\
OLC & 69,883 & 46,556 & 15,530 & 720 & - & 198 \\
AFR & - & 159,637 & 55,522 & - & - & 2,051 \\
\hline
\end{tabular}

\footnotetext{
18 ABARE's Australian Forest and Wood Products http://www.abare.gov.au/publications_html/forestry/forestry_09/forestry_09.html

${ }^{19}$ Illegalities may result in extraction of timber without permission or from protected areas, extraction of protected species or exceeding the agreed limits, misdeclaration to customs, etc.

${ }^{20}$ Taiga Rescue Network, Sweden, www.taigarescue.org
} 


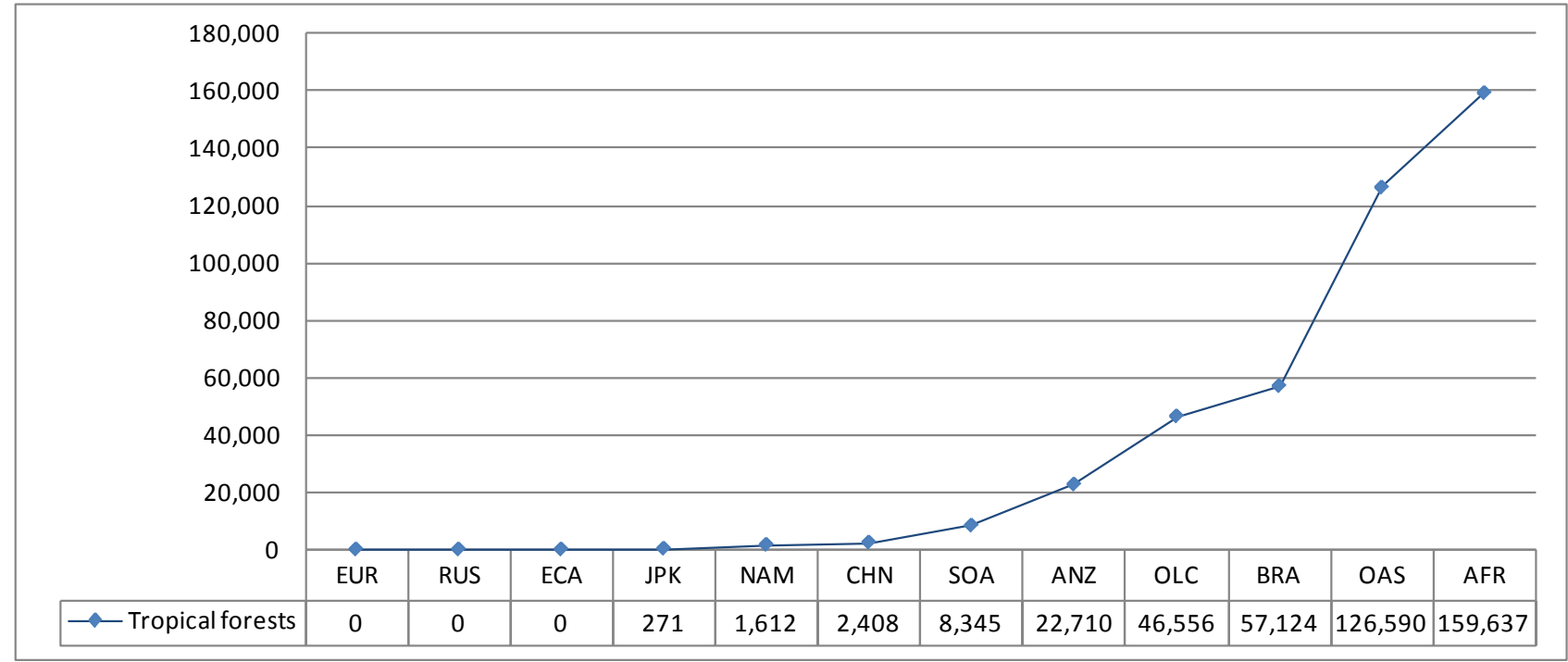

Figure 2. NPV per hectare of WFPs by world region for tropical forests, stock values (2005US\$/ha)

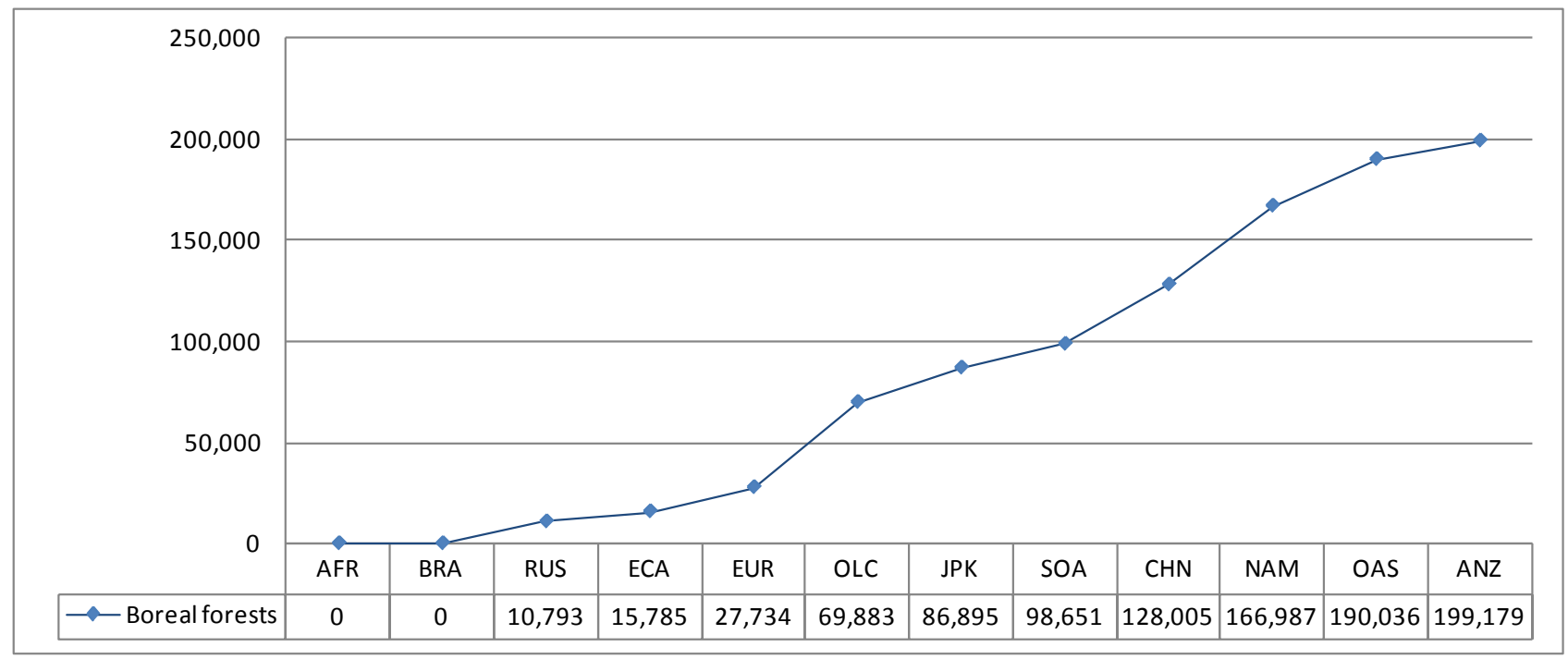

Figure 3. NPV per hectare of WFPs by world region for boreal forests, stock values (2005US\$/ha)

\subsection{Regulating services}

\subsubsection{Methodology}

Regulating services in forests include a vast array of services such as climate regulation (through carbon sequestration), water regulation (runoff control, aquifer recharge) and purification, erosion control, natural hazard control, pollination, and biological pest control. In this study we focus only on the role of carbon services provided by forest biomes as a way of mitigating greenhouse gases in the atmosphere. In 
this context it is important to distinguish between carbon sequestration and carbon storage. The first is the process of carbon cycling which is captured from the atmosphere by trees through physical and biological processes, and is usually estimated during one year of the tree growth. Instead, the latter refers to the amount of $\mathrm{CO}_{2}$ that is stocked by forest biomass, above and below-ground throughout their entire vegetative cycle.

The approach used in this study analyses the carbon currently stocked in the forest biomes and evaluates the changes that would occur in year 2050. The methodological framework for valuing carbon stocks is built on two phases. First, we identify the biomass carbon capacity by forest type and world region (measured as ton of $\mathrm{C}$ stocked per hectare, tC/ha). Secondly, we compute a value of carbon stocked per hectare for a future scenario in 2050, based on different assumptions on climate change mitigation strategies.

Quantities of carbon stocks (above- and belowground biomass) are drawn from two studies, Myneni et al. (2001) and Gibbs (2007). Myneni et al. (2001) provides estimates of carbon stocks for temperate and boreal forest in Canada, Northern America, China, Japan, Russia, Finland, Sweden, Eurasia and South Eastern Asia. Gibbs (2007) provides estimates of carbon stocks for tropical and warm-mixed forests in Brazilian Amazon, Latin America, Sub-Saharan Africa and Tropical Asia (Table 7).

For world regions not directly covered by these two studies, their forests' capacity for storing carbon is assumed to be equal to the countries that are located in the same geographical regions and covered by the literature. In our framework, carbon stocks vary mainly according to two factors: forest type (tree species having different biomass) and forest area. Tropical and warm mixed forests show the highest carbon capacity, as expected, with the maximum levels being registered in AFR, SOA and BRA. 
Table 7. Biomass carbon capacity in the world forests (tC/ha)

\begin{tabular}{lccrrrr}
\hline $\begin{array}{l}\text { World } \\
\text { Region }\end{array}$ & Boreal & Tropical & $\begin{array}{r}\text { Warm- } \\
\text { mixed }\end{array}$ & $\begin{array}{r}\text { Temperate } \\
\text { mixed }\end{array}$ & $\begin{array}{r}\text { Cool } \\
\text { coniferous }\end{array}$ & $\begin{array}{r}\text { Temperate } \\
\text { deciduous }\end{array}$ \\
\hline NAM & $37.37^{*}$ & $92^{* *}$ & $92^{* *}$ & $51^{*}$ & $37.37^{* *}$ & $51^{*}$ \\
EUR & $37.37^{*}$ & - & $92^{* *}$ & $59.4^{*}$ & $37.37^{* *}$ & $59.4^{*}$ \\
JPK & $37.37 * *$ & $149 * *$ & $100^{* *}$ & $47.35^{*}$ & $37.37^{* *}$ & $47.35^{*}$ \\
ANZ & $37.37 * *$ & $149^{* *}$ & $134^{* *}$ & $51^{* *}$ & - & $51^{* *}$ \\
BRA & - & $186^{*}$ & $168^{*}$ & - & - & - \\
RUS & $37.37^{*}$ & - & $92^{* *}$ & $37.98^{*}$ & $37.37^{* *}$ & $37.98^{*}$ \\
SOA & $59.4^{* *}$ & $225^{*}$ & $180^{*}$ & $168^{* *}$ & $59.4^{* *}$ & $168^{* *}$ \\
CHN & $25.77^{*}$ & $96^{* *}$ & $78^{* *}$ & $25.77^{*}$ & $25.77^{* *}$ & $25.77^{*}$ \\
OAS & $59.4^{* *}$ & $92^{*}$ & $78^{* *}$ & - & - & $59.4^{*}$ \\
ECA & $37.98^{*}$ & - & - & $59.4^{*}$ & $37.98^{* *}$ & $59.4^{*}$ \\
OLC & $34^{* *}$ & $149^{*}$ & $134^{*}$ & $59.4^{* *}$ & - & $34.88^{*}$ \\
AFR & - & $200^{*}$ & $168^{* *}$ & - & - & $59.4^{* *}$ \\
\hline
\end{tabular}

Note: (*) Directly reported from the original studies by forest type and geographical region. (**) Transferred from the original studies to similar world regions. Source: R.B. Myneni et al. (2001); H.K. Gibbs (2007).

As regards the economic valuation, for the price of carbon, we refer to the WITCH model (World Induced Technical Change Hybrid model) developed by FEEM (2008), (Bosetti et al, 2009; Bosetti et al, 2007) ${ }^{21}$. This is an Integrated Assessment Model (IAM) built to assess the impacts of climate policies on the global and regional economy. The model provides, for different future scenarios, the price of carbon permits, the GDP loss, the consumption loss and the total GHG abetment. The carbon market shows the evolution over time of the market price of emissions permits traded in a global market. In the present analysis we use a scenario where all technologies and policies are available, including a broad range of mitigation strategies with immediate and global collaborative action on climate change mitigation. Within this scenario two settings are used to compute price of carbon for 2050: 640ppm $\mathrm{CO}_{2}$ equivalent and 535ppm $\mathrm{CO}_{2}$ equivalent, the former providing a lower-bound price of permits at 136 US\$ per ton of CO2, and the latter corresponding to an upper-bound price of 417 US\$ per ton of $\mathrm{CO}_{2}$. Prices per ton of $\mathrm{CO}_{2}$ refer to a stock value, which have been converted into prices per ton of carbon (tC) and lastly translated into average values per hectare:

Eq.5 $\quad V_{w r, b}=\left(t C / h a_{w r, b}\right) * \$ / t C$

\footnotetext{
${ }^{21}$ Fondazione Eni Enrico Mattei, WITCH model version 2008. Available at: http://www.witchmodel.org/simulator.
} 
Where $V_{w r, b}$ is the value per hectare by world region $w r$ and forest biome $b, t C / h a_{w r, b}$ denotes the tons of carbon stocked per hectare, and $\$ / t C$ is the estimated price per ton of carbon stocked.

\subsubsection{Results}

Results about the projected stock values per hectare of carbon for year 2050 are reported in Table 8. As expected, the highest values are registered for tropical and warm mixed forests in AFR, SOA and BRA, due to the high capacity of carbon sequestration in these forest biomes. This is also confirmed by a study conducted by Lewis (2009) showing that $18 \%$ of the carbon dioxide is actually absorbed by tropical forests in Africa, Asia and South America ${ }^{22}$.

Biomes represent the most important factor explaining the variation in forest carbon stocks, as they correspond to different bioclimatic factors, such as temperature, geological features and precipitation patterns. The average stock values may vary within the same forest biome, according to the carbon capacity as reported in Table 7 which depends mainly on the specific tree species present in the biome, having different biomass.

The values presented are nevertheless subject to a number of limitations, as forest carbon stocks vary within each biome according to many factors, not considered in the studies of Myneni et al. (2001) and Gibbs et al (2007), which provide instead an average value for the biomass carbon capacity using the biome-average datasets ${ }^{23}$. The factors not considered in this approach include slope, elevation, drainage, soil and land-use type. Furthermore, the studies used to compute a biome average value refer to mature stands and to specific forest patches. This value has therefore some limitation in representing adequately the variation within a forest biome and a country. Nevertheless, biome average values are routinely used to estimate carbon stocks as they are commonly available and because they represent the only consistent source of information about forest carbon (Gibbs et al, 2007). A further limitation of this analysis is that it does not account for different land uses of forests which could be associated with lower carbon stocks such as forest area designated to plantations. Finally, the studies of Myneni et al (2001) and Gibbs et al (2007) do not cover all the geographical regions, so that the available figures have been transferred from the original study-sites to regions with similar forest types, assuming for the latter the same carbon capacity.

${ }^{22}$ University of Leeds (2009, February 19). Ireleases/2009/02/090218135031.htm "One-fifth Of Fossil-fuel Emissions Absorbed By Threatened Forests". ScienceDaily. http://www.sciencedaily.com /releases/2009/02/090218135031.htm.

${ }^{23}$ The estimates are based on biome-average datasets where a single representative value of forest carbon per tonne of C per hectare is applied to broad forest categories or biomes (Gibbs et al, 2007). 
Lastly, it is important to note that the carbon storage capacity of forests is a complex and dynamic process. For example, this capacity depends, inter alia, of the type of the forest under consideration and respective location. Furthermore, the maximum storage capacity of a forest is attained after a long period of time. The current knowledge of the dynamic nature of carbon storage in forests is limited. For simplistic reason, it leads us to a major assumption that the projected stocked carbon in forest biomes in the future scenario of policy inaction is linearly related to the changes of forest extension. We acknowledge that future advancement of such kind of knowledge is essential to improve the preciseness of economic valuation results.

Figure 4 presents the variation among world regions in projected stock values of carbon in 2050 for tropical forests, characterized by the highest stocks of carbon.

Table 8. Projected stock values per hectare of carbon sequestered by world region and forest biome (2050US\$/ha)

\begin{tabular}{lccccccccccccc}
\hline $\begin{array}{l}\text { World } \\
\text { Region }\end{array}$ & \multicolumn{2}{c}{ Boreal } & \multicolumn{2}{c}{ Tropical } & Warm-mixed & \multicolumn{2}{c}{$\begin{array}{c}\text { Temperate } \\
\text { mixed }\end{array}$} & Cool coniferous & $\begin{array}{c}\text { Temperate } \\
\text { deciduous }\end{array}$ \\
\hline & LB & UP & LB & UP & LB & UP & LB & UP & LB & UP & LB & UP \\
NAM & 18,707 & 57,038 & 46,053 & 140,419 & 46,053 & 140,419 & 25,529 & 77,841 & 18,707 & 57,038 & 25,529 & 77,841 \\
EUR & 18,707 & 57,038 & - & - & 46,053 & 140,419 & 29,734 & 90,662 & 18,707 & 57,038 & 29,734 & 90,662 \\
JPK & 18,707 & 57,038 & 74,586 & 227,418 & 50,058 & 152,629 & 23,702 & 72,270 & 18,707 & 57,038 & 23,702 & 72,270 \\
ANZ & 18,707 & 57,038 & 74,586 & 227,418 & 67,077 & 204,523 & 25,529 & 77,841 & - & - & 25,529 & 77,841 \\
BRA & - & - & 93,108 & 283,891 & 84,097 & 256,417 & - & - & - & - & - \\
RUS & 18,707 & 57,038 & - & - & 46,053 & 140,419 & 19,012 & 57,969 & 18,707 & 57,038 & 19,012 & 57,969 \\
SOA & 29,734 & 90,662 & 112,630 & 343,416 & 90,104 & 274,733 & 84,097 & 256,417 & 29,734 & 90,662 & 84,097 & 256,417 \\
CHN & 12,900 & 39,333 & 48,056 & 146,524 & 39,045 & 119,051 & 12,900 & 39,333 & 12,900 & 39,333 & 12,900 & 39,333 \\
OAS & 29,734 & 90,662 & 46,053 & 140,419 & 39,045 & 119,051 & - & - & - & - & 29,734 & 90,662 \\
ECA & 19,012 & 57,969 & - & - & - & - & 29,734 & 90,662 & 19,012 & 57,969 & 29,734 & 90,662 \\
OLC & 17,020 & 51,894 & 74,586 & 227,418 & 67,077 & 204,523 & 29,734 & 90,662 & - & - & 17,460 & 53,237 \\
AFR & - & - & 100,116 & 305,259 & 84,097 & 256,417 & - & - & - & - & 29,734 & 90,662 \\
\hline
\end{tabular}

Note: $L B=$ lower bound; $U B=$ upper bound. 


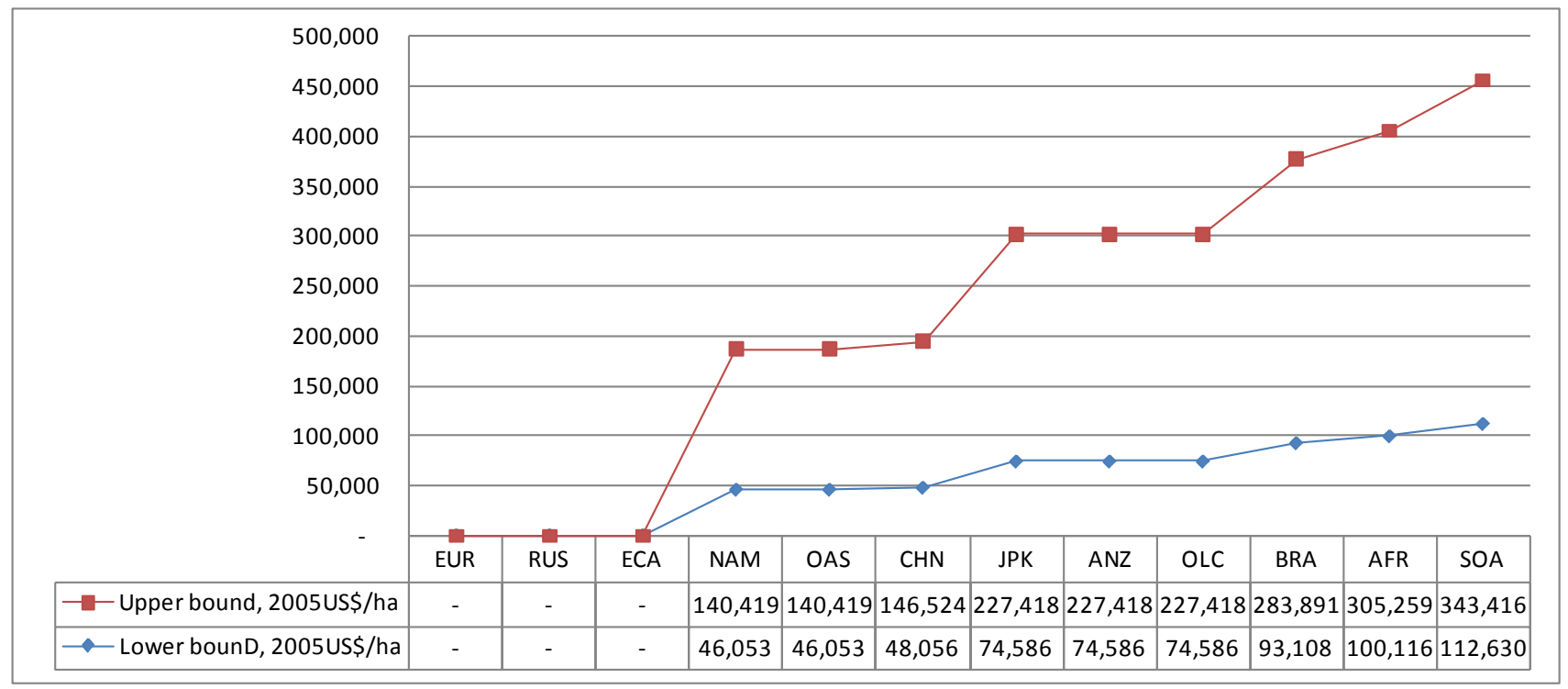

Figure 4. Projected stock values per hectare of carbon sequestered in tropical forests by world regions (2050US\$/ha)

\subsection{Cultural services: recreation and passive use}

\subsubsection{The meta value-transfer model}

Not being traded in regular markets, forest recreation and passive use values can nevertheless be captured by the concept of Willingness To Pay (WTP) ${ }^{24}$ using non-market valuation approaches, either stated or revealed methods. In this paper, in order to assure a worldwide perspective, the estimation of cultural services relies on the body of evidence providing WTP estimates of forest recreation and passive use values, currently available from the environmental valuation literature.

The literature retrieval process ${ }^{25}$ comprised checking several economic databases (among others EconLit, EVRI database and IUCN database for forest studies), reference chasing, and approaching key scholars in the field. This resulted in two sets of 22 and 21 studies providing 59

\footnotetext{
${ }^{24}$ WTP is a measure of non-market environmental dimensions now widely accepted by the research community. We are however fully aware about it has often raised ethical objections. Besides, the reliability of such estimates, especially regarding passive use values, has sometimes showed to be significant. For this reason we have included in our meta-analyses dataset only estimates from published papers assuring a high level of analysis.

${ }^{25}$ Part of the literature review and computations of standardized marginal values per hectare per year in US\$2000 has been conducted within Ojea, E., Nunes, P.A.L.D. and M.L.G. Loureiro (2008). Further details are available upon request to the authors.
} 
and 27 usable estimates of forest recreational and passive use values, respectively (see Table A4 in Annex for the complete list of studies). The WTP figures selected from the literature refer only to annual values, which are converted into stocks in a second step.

Available WTP estimates refer to a range of forest biomes - temperate, warm-mixed, tropical and boreal forests - but cover only a part of world regions, with majority of case studies and estimates referring to Europe (EUR) and North America (NAM). Since available forest cultural value estimates are jeopardized in space, a three-steps meta value-transfer approach was applied in order to provide a worldwide estimation. Firstly, we employed meta-regression to detect statistically significant variables explaining the variance of WTPs estimates for forest recreational and passive use values in the literature. Secondly, we applied value transfer techniques to transfer available estimates to unexplored world regions, and scaling them up from the country to the world region level. Finally, worldwide estimates for the year 2000 were projected to 2050. Below we provide a detailed methodological description.

\section{The meta-regression model}

Following equation Eq. $6^{26}$, two meta-regression functions - one for recreation and one for passive use values - were estimated. To our knowledge, these are the first meta-regressions in the literature providing a synthesis of specific forest ecosystem services worldwide. A recent meta-regression by Ojea et al. (2010) has studied interactions between forest ecosystem values and the various ecosystem services they provide. However it has the theoretical limitation of synthesizing both market and non-market forest valuation data, for any type of MEA service category (provisioning, regulating and cultural), thus mixing pure market prices with implicit prices. Our exercise considers only WTP values. Original reported values per year (per household or per visit) were converted to value per hectare per year when necessary with simple calculations by employing the area of the forest and/or the number of households.

Eq. $6 \quad V=\alpha+\beta_{\text {site }} \log X_{\text {site }}+\beta_{\text {forest }} X_{\text {forest }}+u$

$V$ is the forest value (either recreational or passive use) per hectare per year (the so-called effect size), $a$ is the constant term, the betas represent the vectors of the coefficients to be estimated, and associated with the following types of explanatory variables: forest specific $\left(X_{f o r e s t}\right)$, and context specific $\left(X_{\text {site }}\right)$, while $u$ represents a vector of residuals. Explanatory variables are presented in Table 9. Context specific

\footnotetext{
${ }^{26}$ This functional form proved to be the best specification in terms of statistical performance.
} 
variables reflect the income level (measured as PPPGDP) and the population density in the study area. Forest specific variables reflect the size of the forest area and the type of forest in each case study.

Table 9. List of variables used in the meta-regression models

\begin{tabular}{ll}
\hline $\begin{array}{l}\text { Dependent variable } \\
\text { WTP }\end{array}$ & Value per hectare per year [USD 2000] \\
\hline $\begin{array}{l}\text { Explanatory variables } \\
\text { INCOME }\end{array}$ & $\begin{array}{l}\text { Purchasing power parity GDP level in the study area } \\
\text { [PPP GDP] } \\
\text { Population in the study area [million] } \\
\text { POP }\end{array}$ \\
SIZE & $\begin{array}{l}\text { Size of the forest area designated to recreation or } \\
\text { conservation [hectares] }\end{array}$ \\
Forest type & Temperate forest: takes on value 0,1 \\
TEMP & Warm-mixed forest: takes on value 0,1 \\
WARM & Boreal forest: takes on value 0,1 \\
BOREAL & Tropical forest: takes on value 0,1 \\
TROP &
\end{tabular}

The results of meta-regressions are presented in Table 10. Both for forest recreational and passive use values, results show that WTP estimates increase as the level of income increases, according to economic theory. Similarly, population density has a positive effect on WTPs, thought resulting to be statistically significant only for passive use values. Passive values (such as forest pure existence) are indeed not linked to a direct personal experience of forest ecosystems, and we can thus expect to notice a positive correlation with the population of world regions.

As expected, the size of forest areas affects WTPs in a statistically significant way, showing a negative coefficient for both cultural values. The bigger the stock of forests available, the lower the WTP for the cultural values it provides in per hectare terms. This result confirms what found in previous metaanalyses of ecosystem values such as Ojea et al. (2010), Ghermandi et al. (2007) or Woodward and Wui (2003) for wetlands, as well as in the non-market valuation literature (Loomis et al. 1993). On the other hand, forest types do not lend themselves to be statistically significant explanatory factors. The metaanalysis of forest ecosystem services by Ojea et al. (2010) also reports mixed results on the effect of the type of forest biome. 
Table 10. Meta-regressions results for the recreational and passive use values datasets

\begin{tabular}{lll}
\hline Variables & $\begin{array}{l}\text { Forest recreational use } \\
\text { Coefficiets }\end{array}$ & $\begin{array}{l}\text { Forest passive use } \\
\text { Coefficients }\end{array}$ \\
\hline Dependent & & \\
\hline WTP & & \\
\hline $\begin{array}{l}\text { Explanatory } \\
\text { logINCOME }\end{array}$ & $0.6252^{*}$ & $0.7455^{*}$ \\
logSIZE & $-0.4265^{* * *}$ & $-0.3935^{* *}$ \\
logPOP & 0.3876 & $0.6388^{*}$ \\
TEMP & - & -1.0082 \\
BOREAL & 0.0908 & - \\
WARM & 0.2200 & 1.5206 \\
Constant & -1.6837 & 5.4694 \\
\hline Obs. number & 59 & 27 \\
$\mathrm{r}^{2}$ & 0.4707 & 0.8298 \\
\hline
\end{tabular}

Note: * means $p<0.05$, ** means $p<0.01$, *** means $p<0.001$

The value-transfer and scaling-up model

In the second estimation step, using statistically significant coefficients resulting from the metaregressions, we applied the value transfer model presented in Eq. 7 to estimate, respectively, forest recreational and passive use values worldwide. Prior to this, all annual cultural values have been converted into stock values following Eq. 1, in order to allow a direct comparison with the estimations of provisioning and regulating services.

In value transfer, already available estimates (known as study site) are adjusted and transferred to unexplored policy contexts (know as policy site) (see e.g. Florax et al., 2000). In this paper, study site values are those of Europe, for which the majority of studies are available. The adjustments consider the effects on WTP's magnitude of the following elements, whenever statistically significant: i) size of the forested area, $\sigma$, ii) income level, $\gamma$, and iii) population density, $\delta$, in the world region. The $\delta$ coefficient is applied only to the passive use dataset.

Eq. $7 \quad V_{W R}=V_{E u}^{*}\left(\frac{N_{W R}}{N_{E u}}\right)^{\delta}\left(\frac{S_{E u}}{S_{W R}}\right)^{\sigma}\left(\frac{P P P G D P_{W R}}{P P P G D P_{E u}}\right)^{\gamma}$

The notations $W R$ and $E u$ denote figures referring to, respectively, the $W R_{\text {th }}$ world region and the study site Europe region. $V_{W R}$ is the estimated WTP stock value per hectare (either recreational or passive use) in the $W R_{\text {-th }}$ world region. $V_{E u}^{*}$ is the WTP stock value per hectare (either recreational or passive use) in 
the study site world region. $S$ denotes the forest area designated to recreation or conservation. $N$ denotes the number of households, and PPPGDP indicates the GDP adjusted using Purchasing Power Parity (PPP) taken from World Bank World Development Indicators. The source of data on forest areas is the COPI Globio model, while percentages of forest areas designated to recreation or conservation for each world region are taken from FAO/FRA2005.

The transfer exercise was applied to the Europe mean and median WTP stock values (for recreational and passive use), estimated by averaging mean and median WTP figures available for each forest biomes in Europe (see Figures 5 and 7).

Projections to year 2050

Lastly, following the inter-temporal transfer in Eq.8, values were projected from 2000 to 2050, using the 2050 projections on population density, income and forest areas provided by the IMAGEGLOBIO model ${ }^{27}$ :

Eq. $8 V_{W R i, T_{1}}=V_{W R, T_{0}}\left(\frac{N_{W R, T_{1}}}{N_{W R, T_{0}}}\right)^{\delta}\left(\frac{S_{W R, T_{0}}}{S_{W R, T_{1}}}\right)^{\sigma}\left(\frac{P P P G D P_{W R, T_{1}}}{P P P G D P_{W R, T_{0}}}\right)^{\gamma}$

Where $T_{0}$ is the baseline 2000 year and $T_{1}$ is the projection year 2050 .

\subsubsection{Results}

Results in the baseline year 2000 are presented in Figures 5 and 7, and discussed below. Overall, the positioning of world regions in terms of mean and median stock values of recreational and passive use services show a rather similar pattern, with the 6 highest estimates always including OECD Asia (Japan and Korea) (JPK), OECD Europe (EUR), North America (NAM), and China Region (CHN). Brazil (BRA) and other Asian Countries (OAS) show the highest variability between recreational and passive use values, which is mainly attributable to the difference in forest area size dedicated to recreation and conservation, respectively.

For passive use, estimates go from 4,711 to 87,948 US\$2000 per hectare. The highest values signal a population effect for $\mathrm{CHN}$, and an income effect combined to a scarce presence of conservation areas in respect to EUR for JPK and NAM. Low values for Russia and Caucasus (RUS) and Australia and New

\footnotetext{
${ }^{27}$ Projections of population and GDP per capita in PPP for year 2050 are provided by the COPI project for each world region, based on World Development Indicators (see Table A5 in the Annex) (Braat et al. 2008).
} 
Zealand (ANZ) are mainly due to the low population density, while low values for other Asian Countries (OAS) and other Latin American and Caribbean countries (OLS) can be explained by the low income level.

For recreation, the range goes from 4,398 to 115,895 US\$2000 per hectare. Similarly to what was discussed for passive use, highest estimates derive from an income effect, in accordance to the theoretical assumption - and empirical evidences - that higher income levels are associated to higher WTP estimates. For OAS, the high marginal value is influenced by the high income level and by very small forest size of Singapore. For South Asia and India (SOA), the high value can be explained as a result of the small forest recreational size registered in Bangladesh and Pakistan; while the low marginal values in NAM are due to large forest recreational areas available.

Regarding Brazil (BRA), whose forests are at the center of a fired debate, recreational values are kept low by the vast area currently dedicated to recreation, while passive use values are kept high by the scarce presence of conservation areas and by the low population density.

Results projected to the year 2050 are presented in Figures 6 and 8. Given the assumption used to derive the 2050 forest areas and socio-economic scenarios in the IMAGE-GLOBIO model - which assume that many aspects of today's world will remain the same for the next 50 years (see Section 2) the relative positioning of world regions do not vary significantly neither for recreational nor for passive use values. However, in absolute terms, the rate of increase of cultural values from 2000 to 2050 is not the same for all world regions, and it also varies between recreation and passive use estimates. For recreation, the highest rates of increase are associated to Russia-Caucasian and China regions, which will quadruplicate values by 2050, and to South Asia and India (SOA), other Asian Countries (OAS), Eastern Europe and Central Asia (ECA) and AFR (Africa), which will triplicate it. With the only exception of China, such trend will mainly be driven by the increasing scarcity of forest areas in tropical and boreal world regions that will push their recreational value up. Differently, the case of China reflects the future slight increase in forest areas in combination with the effect of an increase of both income level and population density. Regarding passive use, the rate of increase in the period 2000-2050 is expected to be even higher and distributed rather homogeneously across all world regions, as a result of the significant reduction of natural forest areas that will interest almost all forest biomes (tropical, boreal, warm mixed and temperate mixed, temperate deciduous). 


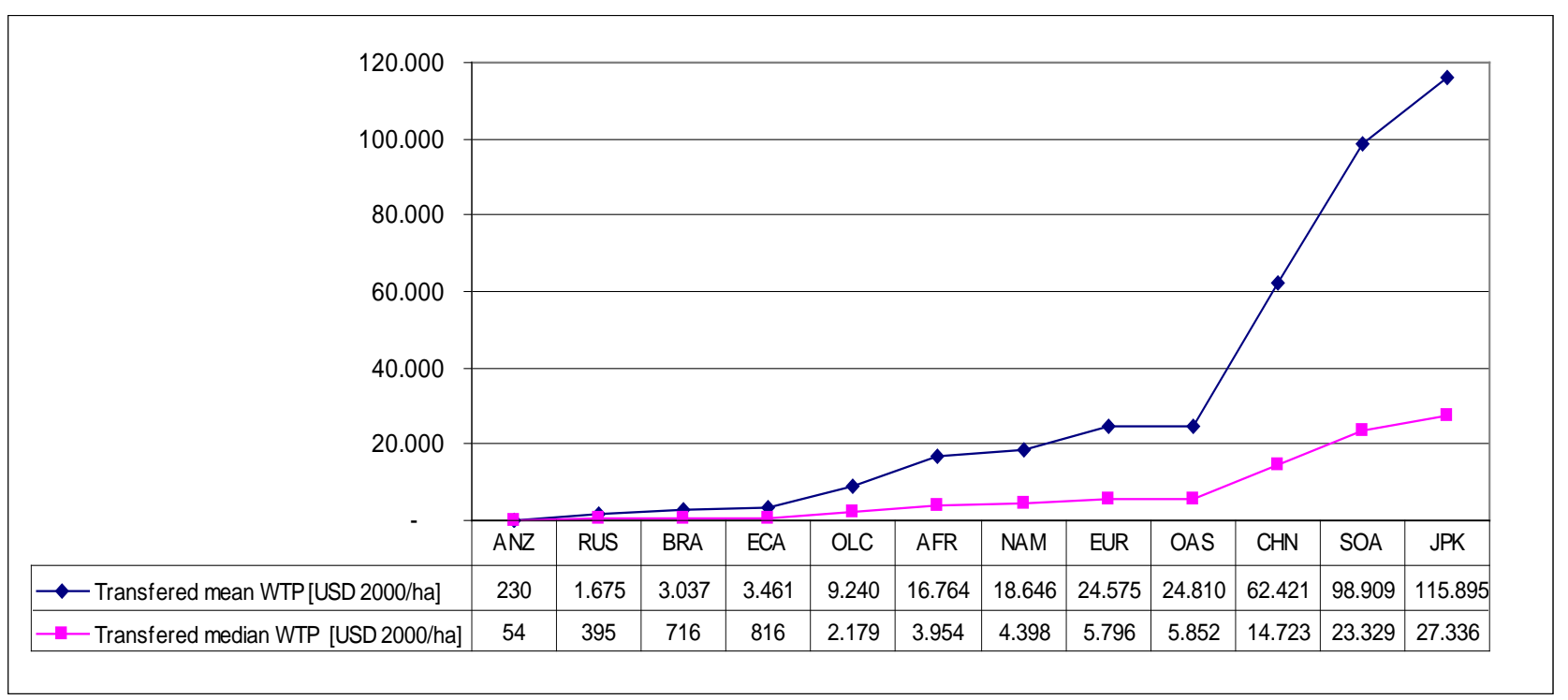

Figure 5. Results of the meta-value transfer for recreational forest use. Upper and lower bound estimates of WTP stock values per world region (2000US\$/ha)

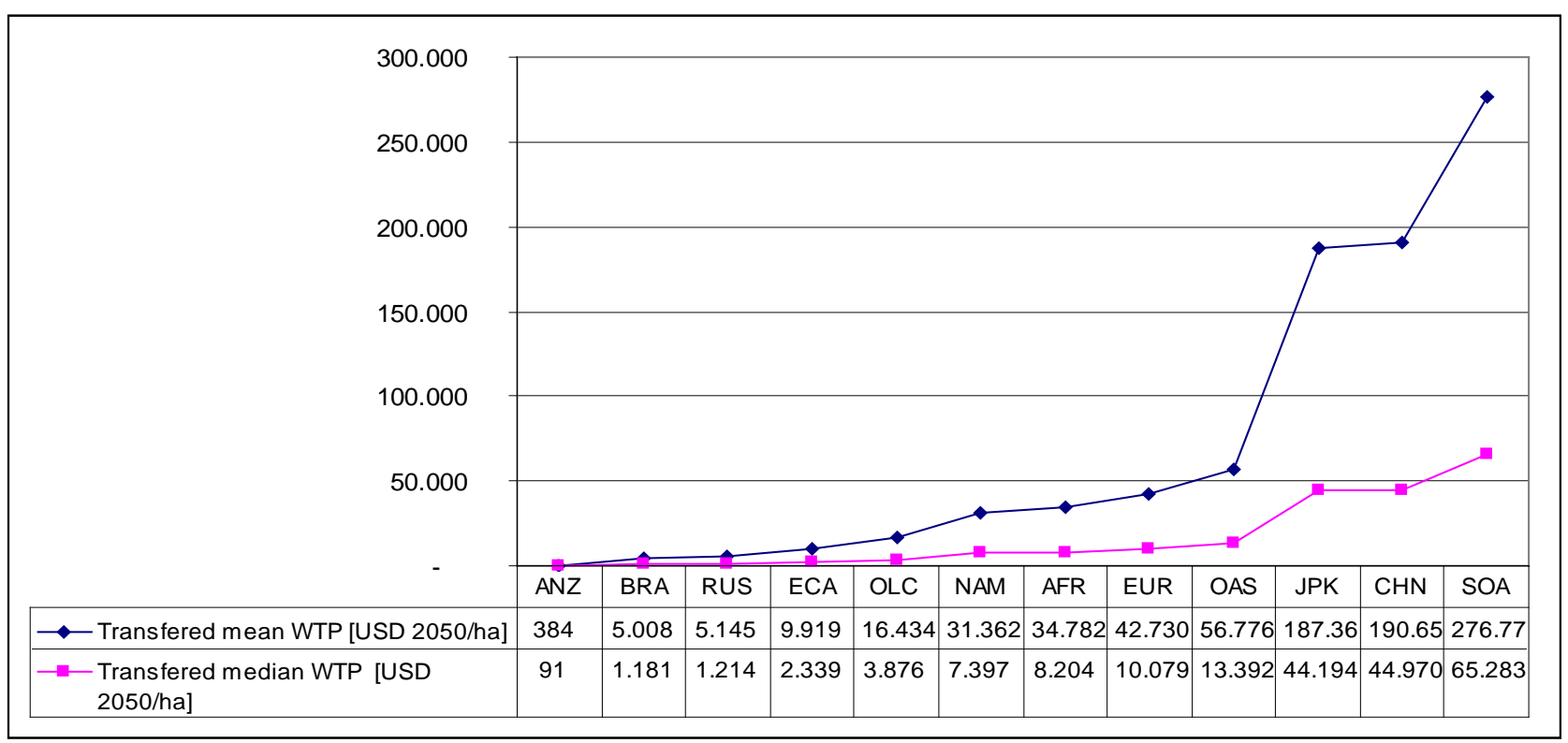

Figure 6. Results of projections to 2050 for recreational forest use. Upper and lower bound estimates of WTP stock values per world region (2050US\$/ha) 


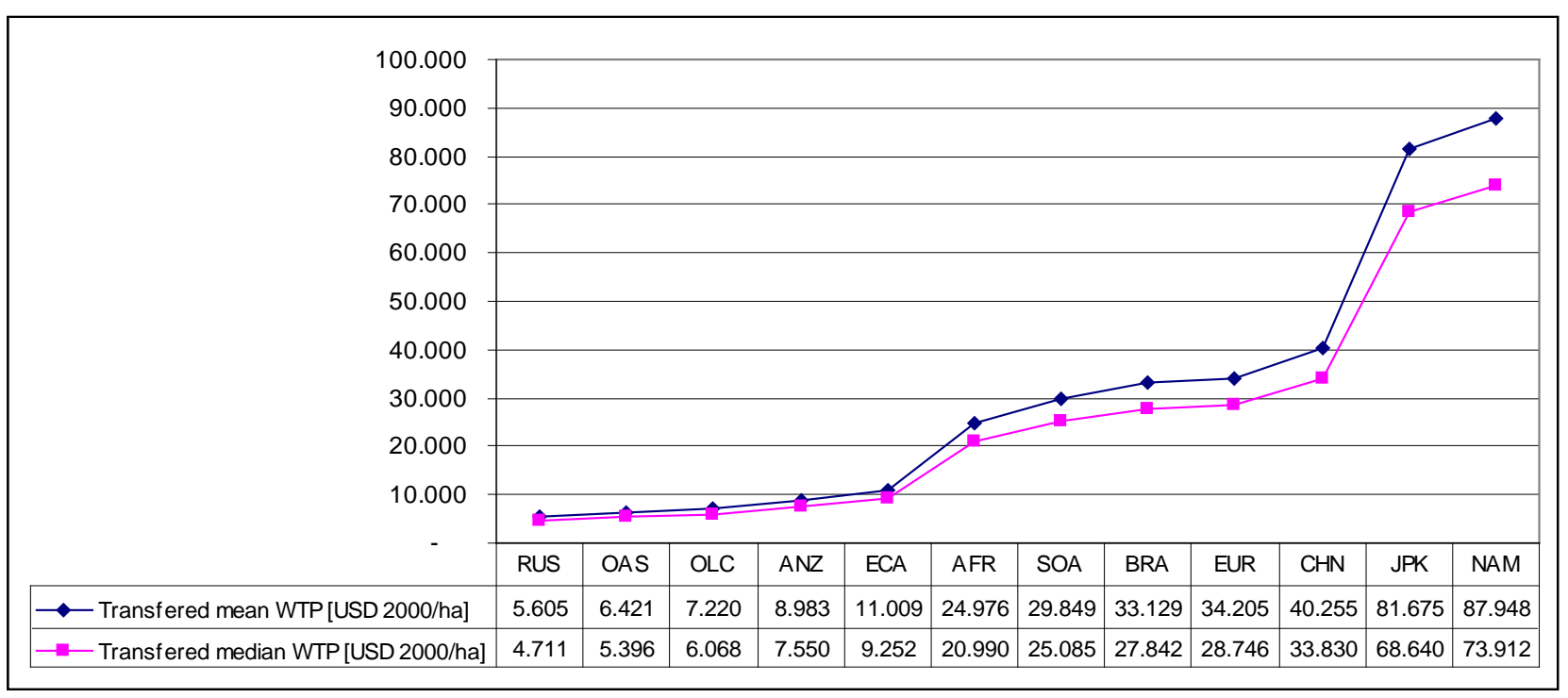

Figure 7. Results of the meta-value transfer for passive forest use. Upper and lower bound estimates of WTP stock values per world region (2000US\$/ha)

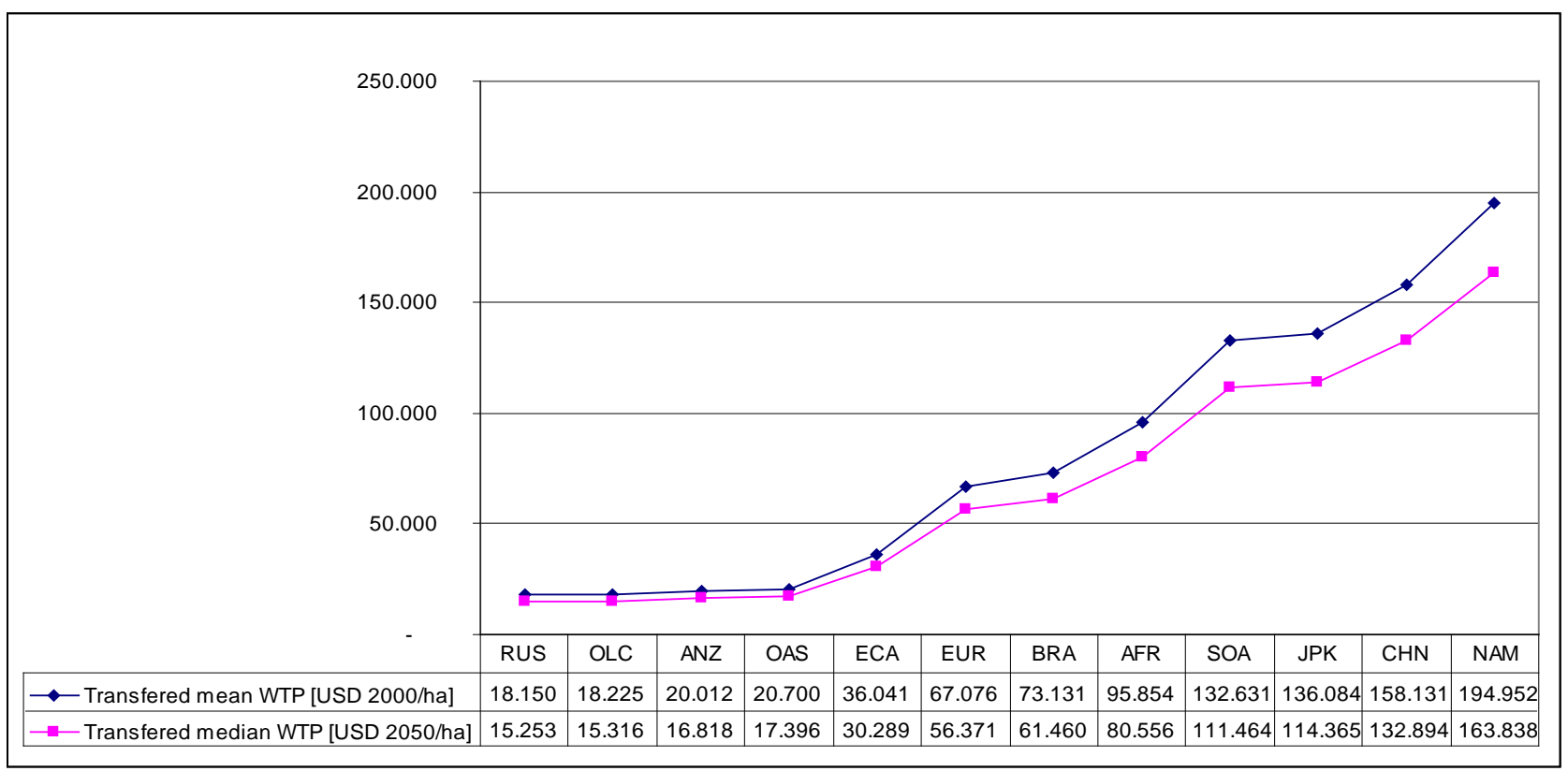

Figure 8. Results of projections to 2050 for passive forest use. Upper and lower bound estimates of WTP stock values per world region (2050US\$/ha) 


\section{Welfare change associated with ecosystem service loss}

In order to estimate the economic value associated with the welfare loss (or gain) of forest EGSs from year 2000 to year 2050, the change in forest area projected for that period (from IMAGE-GLOBIO) is multiplied by the stock values per hectare projected for 2050 for the selected EGSs, by world region and forest biome. The approach allows us to compute changes in stock value of forests, for the selected EGSs, according to three main dimensions: ecosystem service, forest biome and geographical region. The underlying assumption is that the wellbeing of forest ecosystems which is supported by biodiversity does not vary as forest stocks change. This assumption implies a direct proportional relationship between forest stock areas and the stock of the ecosystem services they provide.

As discussed in section 2.3, the IMAGE-GLOBIO model provides projections for natural (relatively untouched) and managed forest (plantations). For wood forest products, we use the projected change in the managed forest, while for non-wood forest products we refer to the change in the total forest area (natural and managed). Carbon sequestration is expected to occur in both natural and managed forests, so all the forest areas are considered for the final computation of loss. As regards the cultural services, these are provided by natural forests, but not all the natural forest area can be considered in valuing the economic loss associated with these services. We use therefore the percentage of forest area designated to recreation (for recreational services) or conservation (for passive use), available from FAO for the year 20005 (FAO/FRA 2005). We do not have, however, information about the variation over time in these percentages for all the world regions. For projections in 2050, we make therefore the simplistic assumption of no variation in the proportion of forest land used for cultural purposes. 
Table 11. Changes in total stocks value of forests, by world region and forest biome, projected to 2050 (bn US\$, 2050)

\begin{tabular}{|c|c|c|c|c|c|c|c|c|c|c|c|c|c|c|}
\hline \multirow[t]{2}{*}{$\begin{array}{l}\text { World } \\
\text { Region }\end{array}$} & \multicolumn{2}{|c|}{ Carbon } & \multirow{2}{*}{$\begin{array}{r}\begin{array}{c}\text { WFPs } \\
\text { \& } \\
\text { NWFPs }\end{array} \\
\text { PE }\end{array}$} & \multicolumn{2}{|c|}{ Recreation } & \multicolumn{2}{|c|}{ Passive use } & \multicolumn{2}{|c|}{ Total } & \multicolumn{2}{|c|}{$\Delta$ value per year } & \multirow[t]{2}{*}{$\begin{array}{l}2050 \text { GDP } \\
\text { (bn.\$) }\end{array}$} & \multicolumn{2}{|c|}{$\begin{array}{c}\% \text { of } 2050 \\
\text { GDP }\end{array}$} \\
\hline & LB & UP & & $\mathrm{LB}$ & UP & LB & UP & LB & UP & $\mathrm{LB}$ & UP & & LB & UP \\
\hline NAM & -75 & -229 & 5,357 & -23 & -96 & $-1,126$ & $-1,340$ & 4,133 & 3,692 & 92 & 82 & 35,700 & 0.26 & 0.23 \\
\hline EUR & 258 & 785 & 559 & -14 & -52 & -152 & -181 & 651 & 1,112 & 14 & 25 & 28,500 & 0.05 & 0.09 \\
\hline JPK & 79 & 241 & 421 & 1 & 2 & 2 & 3 & 504 & 667 & 11 & 15 & 8,200 & 0.14 & 0.18 \\
\hline ANZ & -100 & -305 & 73 & 0 & 0 & -5 & -6 & -32 & -238 & -1 & -5 & 1,800 & -0.04 & -0.29 \\
\hline BRA & $-3,605$ & $-10,993$ & 220 & -13 & -56 & -233 & -277 & $-3,631$ & $-11,105$ & -81 & -247 & 3,900 & -2.07 & -6.33 \\
\hline RUS & -881 & $-2,686$ & 4 & -8 & -11 & -76 & -90 & -961 & $-2,783$ & -21 & -62 & 6,400 & -0.33 & -0.97 \\
\hline SOA & -464 & $-1,414$ & 576 & -52 & -227 & -212 & -252 & -152 & $-1,317$ & -3 & -29 & 26,600 & -0.01 & -0.11 \\
\hline CHN & 14 & 44 & 1,314 & -34 & -174 & -271 & -323 & 1,023 & 861 & 23 & 19 & 45,000 & 0.05 & 0.04 \\
\hline OAS & -318 & -969 & 1,306 & -12 & -50 & -34 & -40 & 943 & 247 & 21 & 5 & 10,600 & 0.20 & 0.05 \\
\hline ECA & -193 & -588 & 10 & -1 & -4 & -24 & -29 & -208 & -610 & -5 & -14 & 2,200 & -0.21 & -0.62 \\
\hline OLC & -268 & -818 & 170 & -1 & -7 & -14 & -17 & -114 & -671 & -3 & -15 & 6,000 & -0.04 & -0.25 \\
\hline AFR & $-1,021$ & $-3,115$ & 1,794 & -9 & -39 & -204 & -243 & 558 & $-1,604$ & 12 & -36 & 14,000 & 0.09 & -0.25 \\
\hline TOT & $-6,574$ & $-20,045$ & 11,806 & -167 & -714 & $-2,350$ & $-2,796$ & 2,715 & $-11,749$ & 60 & -261 & 195,000 & 0.03 & -0.13 \\
\hline $\begin{array}{c}\Delta \text { value per } \\
\text { year }\end{array}$ & -146.09 & -445.45 & 262.35 & -3.71 & -15.88 & -52.21 & -62.13 & 60.34 & -261.10 & 1.34 & -5.80 & - & - & - \\
\hline $\begin{array}{r}\% \text { of } 2050 \\
\text { world GDP }\end{array}$ & -0.07 & -0.23 & 0.13 & -0.002 & -0.01 & -0.027 & -0.032 & 0.03 & -0.13 & 0.001 & -0.003 & - & - & - \\
\hline
\end{tabular}

Note: $L B=$ lower bound; $U B=$ upper bound; $P E=$ point estimate.

Table 11 shows the estimated economic value associated with a change in forest areas in year 2050, resulting from business as usual in the way forests are managed and exploited. We should note that the results refer to a subset of ecosystem services: we could not value for example, most of the regulating services (such a s air quality maintenance, soil quality, water and temperature regulation, natural hazard control), and other provisioning services (such as pharmaceutics and fresh water), due to the difficulties in finding reliable data for value estimates. As the figures show, however, the quantified losses are significant for the four services analyzed: carbon, wood and non-wood forest products, recreation/ecotourism and passive use services. The table reports, for each world region, the lower- and upper-bound economic loss or gain (in billion US\$2050) for each service, the total welfare impact for the four services together, the annual welfare impact from 2000 to 2050, and the corresponding percentage of 2050 GDP.

At a world level, and for the four services under analysis, the estimates show an economic benefit (equal to 2,700 billion US\$2050) when using the lower bound figures, and an economic loss with the upper bound figures (equal to 11,800 billion US\$2050). This corresponds to a variation in the 2050 world 
$\mathrm{GDP}^{28}$, ranging from a benefit of $+0.03 \%$ to a loss of $-0.13 \%$. The world regions that are expected to gain from the business as usual policy in both scenarios (lower and upper bound), include mostly developed countries such as NAM, EUR, JPK, ANZ, but also countries like CHN and OAS. This can be explained mainly by the positive value change engendered by provisioning services (WFPs and NWFPs). For countries like EUR, JPK and CHN, a benefit (even if lower compared to provisioning), is expected also from increased carbon stocks due to an expansion in total forest area projected in these regions (natural and managed). All the other world regions show an economic loss due to policy inaction, with the highest loss expected in Brazil, ranging from 2\% to 6\% of 2050 GDP (corresponding to a loss of 3,600-10,900 billion US\$2050). This economic loss is attributable to a reduction in the forest area estimated around $12 \%$ in natural forests (and 10\% in total forest area). This result is mainly explained by the projected loss of carbon due to deforestation in tropical forests, which present a high value of carbon stocks. For the other world regions, the loss ranges from $0.01 \%$ to $0.97 \%$ of 2050 GDP. RUS region presents, after BRA, the highest loss in terms of 2050 GDP (0.33\% to $0.97 \%)$ attributable to a $4.2 \%$ decrease in forest area, followed by ECA $(0.21 \%$ to $0.62 \%)$, where the forest area is expected to decrease by $27 \%$. For both of them, the major costs are attributable to carbon loss.

In terms of the specific services under analysis, carbon shows the major economic loss, ranging from 6,500 to 20,000 billion US\$2050 (0.07\% to $0.23 \%$ of 2050 GDP). The loss is expected mainly in BRA, as already mentioned, followed by AFR, RUS and SOA. Passive use (conservation values) and recreational services follow with a loss of respective 2,300 to 2,800 billion US\$ 2050 (0.027\% to 0.032\% of 2050 GDP), and 170 to 700 billion US\$2050 (0.002\% to $0.01 \%$ of 2050 GDP). The major losses of passive use services are expected in NAM, CHN, BRA and SOA, while for recreational services the most important losses are registered in SOA and CHN, followed by NAM. Provisioning services (mainly WFPs) present always an economic gain, due to the projected increase in managed forests, with the highest benefits registered in NAM, AFR, CHN and OAS.

\section{Discussion and conclusions}

The paper reports on the methodology and the estimation of some of the services provided by forest biomes in different world areas, by applying consolidated methods for the monetary valuation of market and non-market goods. The study provides a methodological framework for assessing values per hectare for flows and stocks of different forest ecosystem services and the

${ }^{28}$ GDP projections in 2050 taken from COPI project for each world region, based on World Development Indicators (see Table A5 in the Annex) (Braat et al. 2008). 
related economic loss due to policy inaction by 2050, together with an outline on how to use value-transfer techniques.

The valuation framework is applied to forest biomes, and specifically to some key ecosystems services identified following the Millennium Ecosystem Assessment (MEA, 2005) taxonomy: provisioning services (wood forest products and non-wood forest products), carbon services and cultural services (recreation and passive use values). This selection is based on the availability of data and on their relevance to decision-making. The estimation of such services, although not covering the full range of forest instrumental values, allow the quantification of those values which are expected to be quite relevant to context where it is necessary to make decisions and trade one value against the other. Both market and non-market valuation techniques are applied, depending on the nature of the service under concern. As regards specifically non-market valuation, however, the present study mainly relies on the existing body of knowledge already available in the literature to draw suitable values for forest services, to be scaled up at the global (world regions) level using proper transfer protocols. The valuation framework is built in order to cover, for each ecosystem service, the highest variability in terms of geographical regions and forest biomes.

The first part of the study estimates stock values per hectare for the four EGSs under analysis, for the baseline year and for year 2050. Carbon stocks present, in general, the highest value per hectare, followed by provisioning services, passive use and recreational values. It must be said, however, that values per hectare differ widely according to the world region and the forest biome analyzed.

The second part provides an estimation of the welfare loss (or gain) associated to a change in the forest area projected for the period 2000-2050, estimated in terms of change in total stock values, for the four EGSs analyzed. Final results show that using lower bound or upper bound values per hectare can lead to different welfare impacts. Using the lower bound values leads to a total economic benefit equal to 2,700 billion US $\$ 2050$ (corresponding to $0.03 \%$ of 2050 GDP), while upper bound values produce a loss of around 11,800 billion US $\$ 2050$ (corresponding to $0.13 \%$ of 2050 GDP). The greatest negative impact is projected for Brazil, showing a loss of $2 \%$ to $6 \%$ of 2050 GDP, or 3,600 to 11,000 billion US\$2050 for the EGSs analyzed. This is attributable to a large reduction in the Amazonian forest area, estimated around $12 \%$ in natural forest. The increase in managed forest in the same area, even if quite impressive in percent terms, is not compensating the huge deforestation which is taking place, and the associated degradation of forest ecosystems and related carbon services. Some regions, however, are expected to gain from the policy inaction. These include mainly developed countries (NAM, EUR, JPK and ANZ), and also some developing countries like CHN and OAS. The economic benefit ( $0.05 \%$ to $0.23 \%$ of 2050 GDP) associated with the policy inaction in these regions is due mainly to the revenues generated by 
WFPs, considering that managed forest is projected to rise in all the world regions by 2050. The other world regions are expected to face a loss ranging from $0.01 \%$ to $0.97 \%$ of 2050 GDP, mostly attributable to loss of carbon stocks.

Provisioning services (represented mainly by WFPs) show always an economic benefit, due to the expected increase in managed forests. When using the lower bound estimates, the economic benefits emerging from provisioning services exceed the loss of the other services. However, the economic benefits associated with provisioning services do not reflect a monetary compensation for the expected loss of the other ecosystem services. This is because managed forest areas designated to WFPs (being the dominant part of provisioning in this analysis), especially those consisting in large-scale monoculture tree plantations, have many negative environmental and social impacts, which we were not able to value. These include destruction of native forests in many countries (such as Australia, Brazil, Indonesia and Chile) which is a major cause of biodiversity loss; soil contamination and deterioration caused by use of agrochemical products; negative impacts on water supply and purification; violation of land rights of indigenous peoples which causes social conflicts in several countries (due to rural unemployment, poor work conditions and migration to cities). The most affected by these impacts are indigenous people, women and children. In addition, expansion of forest plantations might have a negative impact for climate change mitigation, due to a possible increase in greenhouse gas emissions caused by the development of pulp and biomass industry. Plantations, especially if monoculture, increase the stress on natural forests instead of reducing it, as they create little employment per each hectare, which encourage exploitation of remaining forest land. Expansion of managed forest should not therefore be seen as a policy to reduce emissions from forest degradation and deforestation. Another important issue to consider in this context is illegal logging which is quite frequent, even in countries with well established forest laws. The problem has been considered in the past as particularly relevant in tropical forests, but an increasing concern is gaining attention for boreal forests of Russia. This means on the one hand that available statistics on logging are not entirely reliable, and on the other hand that deterioration of forests, related EGSs and biodiversity levels might be more alarming than expected. Appropriate action is therefore required to limit this global trend.

Although useful, the figures provided in this paper represent, in our view, an underestimate of the total social cost that would result from the business-as-usual scenario. First, many important services are excluded from the analysis, such as most of the regulating services (water, soil quality, flood prevention) and other provisioning services such as pharmaceutical products and fresh water. These services are usually estimated by non-market valuation studies which provide site-specific values in local contexts. In order to perform a worldwide estimation of the welfare loss, these local values have to be transferred and 
scaled-up from the study-sites to the policy-sites. This requires, however, a substantial number of original studies, which are more difficult to find for the above services.

A second limitation is related to the estimation of the stock value per hectare. While for provisioning services we used net present values, for the other services we did not consider the related costs (such as conservation or recreational costs), as this information is very difficult to obtain at a worldwide level taking into account the geographical differences.

A further weakness is that the study does not consider land use type as an additional factor influencing the capacity of the ecosystem to supply EGSs. Conversion of natural forests to plantations generates higher profits with immediate positive impacts on human well-being, but in the long run the provision of other services, such as regulating and supporting services (climate, flood control, water, soil formation, biomass production, nutrient cycling), can be durably compromised by the loss of pristine forests. This has not been taken into account in this paper, due to the many scientific uncertainties still surrounding the ecosystem functioning, and the associated relationship between ecosystem degradation and level of service provision. Finally, threshold effects are not taken into account and a proportional relationship is assumed between forest stock areas and the stock of EGS provided.

Our work suggests that any attempt to provide a monetary estimation of ecosystem services still represents a very challenging task for researchers. On the one hand this task is made difficult due to the partial lack of original valuation studies providing reliable estimates of the WTP for forest values. On the other hand, the worldwide approach adopted here will need to be reinforced by taking into consideration the lack of information on the local ecosystem conditions that are expected to influence the results of the valuation.

Despite these limitations, the methodological framework provided in this study is an attempt to consider both market and non-market values in the valuation of natural resources. As highlighted in The Economics of Ecosystems and Biodiversity (TEEB, 2009), most of the services provided by the ecosystems are not captured by conventional macro-economic indicators (such as the GDP), due to the fact that they are not traded in markets. It is therefore important to measure these un-priced benefits, which at the current state of the art, are not taken into account in conventional accounting systems such as the SEEA (System of Economic and Environmental Accounting), except for the Philippine Environment and Natural Resources Accounting Project (ENRAP) which considers both stocks and flows of values associated with natural resources.

Future research developments should go in the direction of understanding if the renewable natural capital stocks are consumed in a sustainable way in the long run, i.e. not exceeding the natural 
regeneration of the stocks. The net present value is the theoretically correct measure to use to value an asset and its depreciation, but it requires numerous assumptions, especially as regards the appropriate discount rate to use. In this perspective further work is needed also to analyze the existing trade-off between competing services, such as timber and regulating or cultural services.

\section{References}

Alkemade R., M. Blackens, R. Bobbin, L. Miles, C. Nellermann, H. Simons, T. Mecklenburg (2006). GLOBIO 3: Framework for the assessment of global biodiversity. In: MNP (2006) Integrated modeling of environmental change. An overview of IMAGE 2.4. NEAA/MNP, Bilthoven: 171-186.

Bakkes, J.A. and Bosch, P.R. (ed.) (2008). Background report to the OECD EnvironmentalOutlook to 2030: overviews, details, and methodology of model-based analysis. Netherlands Environmental Assessment Agency/ MNP. Bilthoven.

Bahuguna, V. 2000. Forests in the economy of the rural poor: an estimation of the dependency level, Ambio, 29, 3,May, 126-129.

Bateman, I., Lovett, A and Brainard, J. 1999. Developing a methodology for benefit transfers using geographical information systems: modelling demand for woodland recreation, Regional Studies, 33, 3, 191-205.

Bellu, L. and Cistulli, V. 1997. Economic Valuation of Forest Recreation Facilities in the Liguria Region (Italy), Working paper GEC 97-08, Centre for Social and Economic Research on the Global Environment, The Value of Forest Ecosystems University of East Anglia and University College London. Bennett, E and Robinson, J. 2000. Hunting ofWildlife in Tropical Forests, Biodiversity Series - Impact Studies, Paper 76,Washington DC:World Bank.

Bockstael, N.E., Freeman, A.M., Kopp, R., Portney, P.R., Smith, K.V. (2000). On measuring economic values for nature. Environ Sci Technol 34:1384-1389.

Bolt, K., Matete, M. and M. Clemens (2002). Manual for Calculating Adjusted Net Savings. Environment Department, World Bank

Bosetti, V., Tavoni, M., De Cian, E., and Sgobbi, A. (2009). The 2008 WITCH Model: New Model Features and Baseline. FEEM Working Paper 2009.085. 
Bosetti, V., Massetti, E., and Tavoni, M. (2007). The WITCH Model. Structure, Baseline, Solutions" by FEEM Working Paper 2007.010.

Braat, L. and Ten Brink, P. (eds.) with J. Bakkes, K. Bolt, I. Braeuer, B. ten Brink, A. Chiabai, H. Ding, H. Gerdes, M., Jeuken, M. Kettunen, U. Kirchholtes, C. Klok, A. Markandya, P. Nunes, M. van, Oorschot, N. Peralta-Bezerra, M. Rayment, C. Travisi, M. Walpole (2008). The Cost of Policy Inaction. The case of not meeting the 2010 biodiversity target. Report of the COPI project, Wageningen and Brussels, May 2008.

Cavendish, W. 1999. Empirical Regularities in the Poverty-Environment Relationship of African Rural Households, Working paper 99-21, Centre for the Study of African Economies, Oxford University.

CBD (2001). The value of forest ecosystems. Secretariat of the Convention on Biological Diversity, Montreal.

Chamshama, S. and Nwonwu, F. 2004. "Forest plantations in Sub-Saharan Africa”, A report prepared for the project Lessons Learnt on Sustainable Forest Management in Africa.

Chase, L., Lee, D., Schulze, W., and Anderson, D. (1998). Ecotourism Demand and Differential Pricing of National Park Access in Costa Rica. Department of Natural Resources, Cornell University, mimeo.

Chomitz KM, Alger K, Thomas TS, Orlando H, Vila Nova P (2005) Opportunity costs of conservation in a biodiversity hotspot: The case of southern Bahia, Environ Dev Econ 10(3):293-312.

Clark, J. (2001). The global wood market, prices and plantation investment: an examination drawing on the Australian experience. Environmental Conservation 28 (1):53-64.

Costanza, R, R.D'Arge, R de Groot, S.Farber, M.Grasso, B.Hannon, K.Limburg, S.Naeem, R.O'Neill, J.Paruelo, R.Raskin, P.Sutton and M van den Belt (1997). The value of the world's ecosystem services and natural capital, Nature, 387(May): 253-260.

Donoghe, E.M., Benson, G.L., and Chamberlain, J.L. (2004). “Sustainable production of wood and nonwood forest products. Proceedings of the IUFRO Division 5 Research Groups 5.11 and 5.12, Rotorua, New Zealand, March 11-15, 2003. US Department of Agriculture, Forest Service, Pacific Northwest Research Station, Portland, Oregon, General Technical Report PNW-GTR-604.

Emerton, L. (1999). Mount Kenya: the economics of community conservation. IIED Evaluating Eden Series, Discussion Paper 4. http://www.iied.org/pubs/pdf/full/7797IIED.pdf 
ERM (Environmental Resources Management) (1996).Valuing Management for Biodiversity in British Forests, Report to UK Forestry Commission.

Evans, D. and Associates, Inc. and ECONorthwest. (2004). Comparative Valuation of Ecosystem Services: Lents Project Case Study. City of Portland Watershed Management Program. June. Retrieved December 1, 2006, from http://www.portlandonline.com/bes/index.cfm?\&a=64845.

FAO (2007). The state of food and agriculture. Paying farmers for environmental services. FAO Agriculture Series No. 38. Rome

FAO/FRA 2005 (2006). Global Forest Resources Assessment 2005: Progress towards sustainable forest management, FAO Forestry Paper no.147, available on website: ftp://ftp.fao.org/docrep/fao/008/A0400E/A0400E00.pdf.

FAO/ForesSTAT is available online at: http://faostat.fao.org/site/381/default.aspx

FAO. 1999. State of the World's Forests, 1999. Third edition. Food and Agriculture Organization of the United Nations, Rome, 1999. http://www.fao.org/forestry/FO/SOFO/SOFO99/sofo99-e.stm

FAO. 1997. State of the World's Forests, 1997. Food and Agriculture Organization of the United Nations, Rome, 1997. http://www.fao.org/forestry .

FAO, 1995. Medicinal plants for conservation and health care. NON-WOOD FOREST PRODUCTS 11. FAO - Food and Agriculture Organization of the United Nations. M-37 ISBN 92-5-104063-X.

Garrod, G.D. and Willis, K. G. (1997). The non-use benefits of enhancing forest biodiversity: A contingent ranking study. Ecological Economics: 45-61.

Ghermandi, A., Van den Bergh, J.C.J.M., Brander, L.M., de Groot, H.L.F., and Nunes. P.A.L.D. (2008). The economic value of wetland conservation and creation: a meta-analysis. FEEM Working Papers 238.

Gibbs H.K., Brown S., Niles J.O. and Foley J.A. (2007). Monitoring and estimating tropical forest carbon stocks: making REDD a reality, Environmental Research Letters 2.

Gordon, Myron J. (1959). "Dividends, Earnings and Stock Prices". Review of Economics and Statistics (The MIT Press) 41 (2): 99-105)

Gurluk, S. (2006). The Estimation of Ecosystem Services' Value in the Region of Misi Rural Development Project: Results From a Contingent Valuation Survey. Forest Policy and Economics, pp. 209-218. 
Hanley, N., Willis, K., Powe, N. and Anderson, M. (2002). Valuing the Benefits of Biodiversity in Forests, Report to the Forestry Commission, Centre for Research in Environmental Appraisal and Management (CREAM), University of Newcastle.

Hanley, N., Wright, R.E., Adamowicz, W.L. (1998). Using Choice Experiments to value the environment. Environmental and Resource Economics, pp. 413-428.

Hoover, W.L. and G., Preston (2006) 2006 Indiana Forest Products Price Report and Trend Analysis. Expert review: FNR-177-W, Purdue University, the USA.

Hope, 2006 C. Hope, The marginal impact of CO2 from PAGE2002: an integrated assessment model incorporating the IPCC's five reasons for concern, Integrated Assessment 6 (2006), p. 1.

Horton, B., Colarullo, G., Bateman, I., Peres, C. (2003). Evaluating non-users willingness to pay for a large scale conservation programme in Amazonia, Environmental Conservation: 139-146.

Kniivila, M., Ovaskainen, V. and Saastamoinen, O. (2002). Costs and benefits of forest conservation: regional and local comparisons in Eastern Finland, Journal of Forest Economics: 131-150.

Kontoleon, A. and Swanson, T. (2003). The willingness to pay for property rights for the Giant Panda: can a charismatic species be an instrument for nature conservation, Land Economics: 483-499.

Kramer, R.A., Sharma, N., and Munashinghe, M. (1995). Valuing Tropical Forests. Methodology and Case Study of Madagascar, World Bank Environment Paper 13.

Lewis, S.L., Phillips, O. L., Baker, T. R., Malhi, Y. \& Lloyd, J. (2006). Tropical forests \& Atmospheric Carbon Dioxide: Current Conditions and Future Scenarios. Pp 147-153. In Avoiding Dangerous Climate Change, Schellnhuber, H J., Cramer, W., Nakicenovic, N., Wigley, T. and Yohe, G (Eds). Cambridge University Press.

Loomis, J., and E. Ekstrand. (1998). Alternative Approaches for Incorporating Respondent Uncertainty When Estimating Willingness-to-Pay: The case of the Mexican Spotted Owl. Ecological Economics 27(1): 29-41.

Markandya, A., Nunes, P.A.L.D., Brauer, I., ten Brink, P. Kuik, O. and M. Rayment (2008) “Review On The Economics Of Biodiversity Loss - Economic Analysis and Synthesis”, Final report for the European Commission, Venice, Italy. 140 pp.

MEA (2005). Ecosystems and Human Well-being: Biodiversity Synthesis, World Resources Institute, Ashington, D.C. 
Mendelsohn, R. and Balick, M. (1995). The value of undiscovered pharmaceuticals in tropical forests. Economic Botany, 49(2), 223-228.

Miller, K and Tangley, L. (1991). Trees of Life: Saving Tropical Forests and their Biological Wealth. Boston: Beacon Press.

MNP (2006) (Edited by A.F. Bouwman, T. Kram and K. Klein Goldewijk), Integrated modelling of global environmental change. An overview of IMAGE 2.4. Netherlands Environmental Assessment Agency (MNP), Bilthoven, The Netherlands.

Mogas, J., Riera, P. and Bennett, J. (2006). A comparison of contingent valuation and choice modelling with second-order interactions, Journal of Forest Economics: 1-30.

Myneni, R.B., Dong, J., Tucker, C.J., Kaufmann, R.K., Kauppi, P.E., Liski, J., Zhou, L., Alexeyev, V. and M.K. Hughes (2001), A large carbon sink in the woody biomass of northern forests, Proc. Natl. Acad. Sci. U. S. A. 98 (26): 14784-14789.

Naidoo, R. and Adamowicz, W.L. (2005). Biodiversity and nature based tourism at forest reserves in Uganda. Environment and Development Economics, pp. 159-178.

OECD (2008) OECD Environmental Outlook to 2030. OECD, Paris.

Ojea, E., Nunes, P.A.L.D. and M.L.G. Loureiro (2008). Impacts of Climate Change and Biodiversity Effects: Evidence from a Worldwide Meta-analysis on Forest Ecosystem Values, mimeo, Fondazione ENI Enrico Mattei, Venice, Italy.

Ojea, E., Nunes, P.A.L.D., Loureiro, M.L. (2010). Mapping Biodiversity Indicators and Assessing Biodiversity Values in Global Forests Environmental \& Resource Economics. DOI 0.1007/s10640-0109381-6.

Pearce, D.W. (1999). Can non-market values save the world's forests? In Roper S. and Park, A. (eds), The Living Forest: the Non-Market Benefits of Forestry. London: The Stationery Office: 5-16.

Pearce, D.W. (1998). Can non-market values save the tropical forests? In Goldsmith, B. (ed), Tropical Rain Forest: a Wider Perspective. London: Chapman and Hall: 255-268.

Pearce, D.W. (1996). Global environmental value and the tropical forests: demonstration and capture, in W.Adamowicz, P. Boxall, M.Luckert, W.Phillips and W.White (eds), Forestry, Economics and the Environment,Wallingford: CAB International, 11-48. Pearce,D.W. 1998.Auditing the Earth, Environment, 40, 2,March, 23-28. 
Pearce, D.W and Moran,D. (1994). The Economic Value of Biological Diversity, London: Earthscan.

Phillips, S., Silverman, R. (2007). Greater than zero: toward the total economic value of Alaska's National Forest wildlands, The Wilderness Society.

Pimm, S. and Raven, P. (2000). Extinction by numbers, Nature, 403(24): 843-845.

Portela R, Wendland KJ, Pennypacker LL (2008). The idea of market-based mechanisms for forest conservation and climate change. In Streck C., O’ Sullivan R., Janson-Smith T. (eds) Forests, Climate Change and the Carbon Market, Oxford University Press.

Portney, P.R. and J.P. Weyant (eds.) 1999. Discounting and Intergenerational Equity. Resources for the Future.

Scarpa, R.,. Chilton, S. M., Hutchinson W. G., Buongiorno, J. (2000). Valuing the recreational benefits from the Creation of Natre Reserves in Irish forests, Ecological Economics.

Shechter, M., Reiser, B., and Zaitsev, N. (1998). Measuring passive use value: Pledges, donations and CV responses in connection with an important natural resource. Environment and Development Economics, pp 457-478.

Siikamaki, J. (2007). Discrete choice survey experiments: A comparison using flexible methods, Journal of Environmental Economics and Management: 122-139.

TEEB - The Economics of Ecosystems and Biodiversity for National and International Policy Makers Summary: Responding to the Value of Nature 2009.

Thomas CD, Cameron A, Green RE, Bakkenes M, Beaumont LJ, Collingham YC, Erasmus BFN, Ferreira de Siqueira M, Grainger A, Hannah L, Hughes L, Huntley B, van Jaarsveld AS, Midgley GF, Miles L, Ortega-Huerta M, Peterson AT, Phillips OL, Williams SE (2004). Extinction risk from climate change, Nature 427: 145-148.

Toman M (1998) Why not to calculate the value of the world's ecosystem services and natural capital, Ecological Economics, 25:57-60.

University of Leeds (2009, February 19). One-fifth Of Fossil-fuel Emissions Absorbed By Threatened Forests. ScienceDaily. Retrieved July 2, 2010, from http://www.sciencedaily.com /releases/2009/02/090218135031.htm 
Walsh, R.G., Loomis, J.B., and Gillman, R.A. (1984). Valuing option, existence, and bequest demand for wilderness, Land Economics 60 (1): 14-29.

Weitzman, M.L. 2001. Gamma Discounting. The American Economic Review, 91(1): 260-271.

Woodward RT, Wui Y (2007) The economic value of wetland services: a meta-analysis, Ecological Economics, 37:257-270.

Van Beukering, P.J.H. (2002) The economic value of tropical forest and its consequences for setting up payment schemes for environmental services: A comparison between the Leuser National Park (Indonesia) and the Iwokrama Forest (Guyana). Seminar proceedings - Issues in international nature conservation, Utrecht University. http://www.bio.uu.nl/pbc/publications/proceedings/Proceedings_Issues_Dec2002-Apr2003a.pdf\#page=21

Van der Heide, C.M., van den Bergh, J.C.J.M, and Nunes, P.A.L.D. (2005) Measuring the economic value of two habitat defragmentation policy scenarios for the Veluwe, The Netherlands. FEEM Working paper.

Verma, M. (2000). Economic Valuation of Forests of Himachal Pradesh. Report to IIED Himachal Pradesh Forestry Review

Zandersen, M., Termansen, M., Jensen, F.S. (2005). Benefit transfer over time of ecosystem values: the case of forest recreation. Working paper FNU-61. http://www.fnu.zmaw.de/fileadmin/fnufiles/publication/working-papers/Working_Paper_FNU61.pdf 


\section{Annex}

Table A1. Forest area by forest biome and landuse type across world regions, year 2000 (1,000ha)

\begin{tabular}{|c|c|c|c|c|c|c|c|c|c|c|c|c|c|}
\hline $\begin{array}{l}\text { Forest biome and } \\
\text { landuse } \\
\end{array}$ & NAM & EUR & JPK & ANZ & BRA & RUS & SOA & CHN & OAS & ECA & OLC & AFR & Total \\
\hline Boreal & 489,618 & 55,531 & 1,990 & 3,475 & 0 & 917,443 & 3,726 & 71,354 & 269 & 2,645 & 17,648 & 0 & $1,563,701$ \\
\hline natural & 461,611 & 39,581 & 1,936 & 3,468 & 0 & 879,865 & 3,234 & 66,357 & 269 & 2,645 & 17,429 & 0 & 1,476,396 \\
\hline managed & 28,007 & 15,950 & 54 & 8 & 0 & 37,578 & 492 & 4,997 & 0 & 0 & 220 & 0 & 87,305 \\
\hline Tropical & 3,614 & 0 & 48 & 5,964 & 345,477 & $\mathbf{0}$ & 1,554 & 3,195 & 186,765 & $\mathbf{0}$ & 211,012 & 145,529 & 903,157 \\
\hline natural & 3,381 & 0 & 45 & 5,683 & 340,870 & 0 & 1,119 & 2,920 & 173,008 & 0 & 204,836 & 139,530 & 871,392 \\
\hline managed & 233 & 0 & 2 & 282 & 4,296 & 0 & 435 & 275 & 13,757 & 0 & 6,176 & 5,999 & 31,455 \\
\hline Warm mixed & 86,804 & 9,746 & 1,172 & 32,450 & 42,699 & 160 & 18,153 & 88,032 & 17,433 & 0 & 53,288 & 18,963 & 368,899 \\
\hline natural & 68,452 & 6,894 & 973 & 31,404 & 42,130 & 154 & 13,371 & 79,285 & 15,711 & 0 & 52,235 & 18,028 & 328,635 \\
\hline managed & 18,352 & 2,852 & 199 & 1,046 & 880 & 6 & 4,782 & 8,747 & 1,722 & 0 & 1,053 & 935 & 40,575 \\
\hline Temperate mixed & 120,630 & 67,370 & 24,021 & 3,171 & $\mathbf{0}$ & 86,269 & 1,656 & 9,194 & $\mathbf{0}$ & 20,445 & 4,609 & $\mathbf{0}$ & 337,365 \\
\hline natural & 101,591 & 48,009 & 21,179 & 3,142 & 0 & 82,144 & 1,216 & 8,357 & 0 & 16,971 & 4,546 & 0 & 287,154 \\
\hline managed &, 039 & 19,361 & 2,842 & 29 & 0 & 125 & 440 & 837 & 0 & 3,474 & 63 & 0 & 50,211 \\
\hline Cool coni & 89,170 & 25,755 & 3,722 & $\mathbf{0}$ & $\mathbf{0}$ & 113,047 & 1,831 & 13,296 & $\mathbf{0}$ & 1,449 & $\mathbf{0}$ & $\mathbf{0}$ & 248,270 \\
\hline natural & 83,749 & 16,022 & 3,523 & 0 & 0 & 107,377 & 1,489 & 12,132 & 0 & 1,419 & 0 & 0 & 225,711 \\
\hline managed & 5,421 & 9,733 & 199 & 0 & 0 & 5,670 & 342 & 1,164 & 0 & 30 & 0 & 0 & 22,560 \\
\hline Temperate decid. & 64,635 & 75,262 & 15,399 & 10,269 & $\mathbf{0}$ & 3,532 & 7,858 & 63,535 & 466 & 815 & 1,270 & 265 & 243,307 \\
\hline natural & 53,046 & 58,956 & 12,591 & 10,029 & 0 & 3,421 & 5,257 & 57,962 & 389 & 747 & 1,229 & 261 & 203,887 \\
\hline managed & 1,589 & 16,306 & 2,809 & 240 & $\underline{0}$ & 112 & 2,602 & 5,572 & 77 & 68 & 41 & 4 & 39,420 \\
\hline Total & 854,471 & 233,664 & 46,353 & 55,329 & 388,176 & $1,120,451$ & 34,778 & 248,605 & 204,933 & 25,355 & 287,827 & 164,757 & $3,664,699$ \\
\hline$\%$ on total & $23.3 \%$ & $6.4 \%$ & $1.3 \%$ & $1.5 \%$ & $10.6 \%$ & $30.6 \%$ & $0.9 \%$ & $6.8 \%$ & $5.6 \%$ & $0.7 \%$ & $7.9 \%$ & $4.5 \%$ & $100 \%$ \\
\hline Total natural & 771,830 & 169,462 & 40,247 & 53,724 & 383,000 & 1,072,961 & 25,685 & 227,013 & 189,377 & 21,782 & 280,274 & 157,819 & $3,393,174$ \\
\hline$\%$ on total & $21.1 \%$ & $4.6 \%$ & $1.1 \%$ & $1.5 \%$ & $10.5 \%$ & $29.3 \%$ & $0.7 \%$ & $6.2 \%$ & $5.2 \%$ & $0.6 \%$ & $7.6 \%$ & $4.3 \%$ & $92.6 \%$ \\
\hline Total managed & 82,642 & 64,202 & 6,106 & 1,605 & 5,176 & 47,490 & 9,093 & 21,592 & 15,556 & 3,573 & 7,553 & 6,939 & 271,525 \\
\hline$\%$ on total & $2.3 \%$ & $1.8 \%$ & $0.2 \%$ & $0.0 \%$ & $0.1 \%$ & $1.3 \%$ & $0.2 \%$ & $0.6 \%$ & $0.4 \%$ & $0.1 \%$ & $0.2 \%$ & $0.2 \%$ & $7.4 \%$ \\
\hline
\end{tabular}


Table A2. Projections of forest area by forest biome and landuse type across world regions, year 2050 (1,000ha)

\begin{tabular}{|c|c|c|c|c|c|c|c|c|c|c|c|c|c|}
\hline $\begin{array}{l}\text { Forest biome and } \\
\text { landuse }\end{array}$ & NAM & EUR & JPK & ANZ & BRA & RUS & SOA & $\mathrm{CHN}$ & OAS & ECA & OLC & AFR & Total \\
\hline Boreal & 485,587 & 57,399 & 2,018 & 3,359 & 0 & 881,769 & 2,966 & 71,565 & 268 & 2,115 & 16,925 & 0 & $1,523,969$ \\
\hline natural & 437,310 & 33,156 & 1,346 & 3,343 & 0 & 843,785 & 1,834 & 61,831 & 268 & 1,407 & 16,593 & 0 & $1,400,873$ \\
\hline managed & 48,277 & 24,242 & 672 & 16 & 0 & 37,984 & 1,131 & 9,735 & 0 & 707 & 332 & 0 & 123,097 \\
\hline Tropical & 3,833 & 0 & 52 & 5,941 & 309,263 & 0 & 1,515 & 3,214 & 180,477 & $\mathbf{0}$ & 211,403 & 142,247 & 857,944 \\
\hline natural & 3,371 & 0 & 51 & 5,458 & 299,232 & 0 & 465 & 2,684 & 156,505 & 0 & 201,931 & 125,706 & 795,403 \\
\hline managed & 461 & 0 & 1 & 483 & 9,354 & 0 & 1,050 & 529 & 23,972 & 0 & 9,473 & 16,541 & 61,864 \\
\hline Warm mixed & 86,821 & 10,028 & 1,274 & 31,180 & 38,223 & 159 & 14,423 & 88,275 & 16,728 & $\mathbf{0}$ & 49,094 & 10,776 & 346,981 \\
\hline natural & 55,204 & 5,559 & 1,180 & 29,469 & 36,984 & 153 & 3,281 & 71,474 & 13,692 & 0 & 47,490 & 7,846 & 272,331 \\
\hline managed & 31,617 & 4,469 & 94 & 1,712 & 1,916 & 6 & 11,142 & 16,800 & 3,036 & 0 & 1,605 & 2,930 & 75,326 \\
\hline Temperate mixed & 120,933 & 69,240 & 25,687 & 3,024 & 0 & 80,017 & 1,229 & 9,206 & 0 & 14,861 & 4,494 & 0 & 328,691 \\
\hline natural & 87,292 & 39,389 & 20,315 & 2,975 & 0 & 75,913 & 208 & 7,599 & 0 & 11,718 & 4,399 & 0 & 249,807 \\
\hline managed & 33,642 & 29,851 & 5,372 & 49 & 0 & 4,104 & 1,021 & 1,608 & 0 & 3,144 & 94 & 0 & 78,884 \\
\hline Cool coniferous & 87,918 & 24,974 & 3,780 & $\mathbf{0}$ & 0 & 108,426 & 1,394 & 13,291 & $\mathbf{0}$ & 1,233 & $\mathbf{0}$ & 0 & 241,016 \\
\hline natural & 78,491 & 10,734 & 2,542 & 0 & 0 & 102,750 & 620 & 11,054 & 0 & 747 & 0 & 0 & 206,939 \\
\hline managed & 9,426 & 14,241 & 1,237 & 0 & 0 & 5,676 & 774 & 2,237 & 0 & 486 & 0 & 0 & 34,077 \\
\hline Temperate decid. & 64,835 & 80,935 & 16,766 & 9,989 & 0 & 3,106 & 7,245 & 63,626 & 440 & 393 & 1,251 & 119 & 248,706 \\
\hline natural & 44,704 & 54,900 & 15,015 & 9,580 & 0 & 2,999 & 1,164 & 52,919 & 305 & 346 & 1,189 & 108 & 183,230 \\
\hline managed & 20,131 & 26,035 & 1,751 & 409 & 0 & 107 & 6,081 & 10,707 & 135 & 47 & 62 & 11 & 65,477 \\
\hline Total & 849,927 & 242,576 & 49,577 & 53,493 & 347,486 & $1,073,477$ & 28,771 & 249,177 & 197,913 & 18,601 & 283,168 & 153,142 & $3,547,307$ \\
\hline$\%$ on total & $24.0 \%$ & $6.8 \%$ & $1.4 \%$ & $1.5 \%$ & $9.8 \%$ & $30.3 \%$ & $0.8 \%$ & $7.0 \%$ & $5.6 \%$ & $0.5 \%$ & $8.0 \%$ & $4.3 \%$ & $100 \%$ \\
\hline Total natural & 706,371 & 143,738 & 40,449 & 50,825 & 336,216 & $1,025,600$ & 7,573 & 207,561 & 170,771 & 14,218 & 271,602 & 133,661 & $3,108,583$ \\
\hline$\%$ on total & $19.9 \%$ & $4.1 \%$ & $1.1 \%$ & $1.4 \%$ & $9.5 \%$ & $28.9 \%$ & $0.2 \%$ & $5.9 \%$ & $4.8 \%$ & $0.4 \%$ & $7.7 \%$ & $3.8 \%$ & $87.6 \%$ \\
\hline Total managed & 143,555 & 98,838 & 9,129 & 2,668 & 11,270 & 47,877 & 21,198 & 41,616 & 27,142 & 4,384 & 11,566 & 19,481 & 438,724 \\
\hline$\%$ on total & $4.0 \%$ & $2.8 \%$ & $0.3 \%$ & $0.1 \%$ & $0.3 \%$ & $1.3 \%$ & $0.6 \%$ & $1.2 \%$ & $0.8 \%$ & $0.1 \%$ & $0.3 \%$ & $0.5 \%$ & $12.4 \%$ \\
\hline
\end{tabular}

Table A3. Total economic value for WFPs and NWFPs (1,000US\$, 2005)

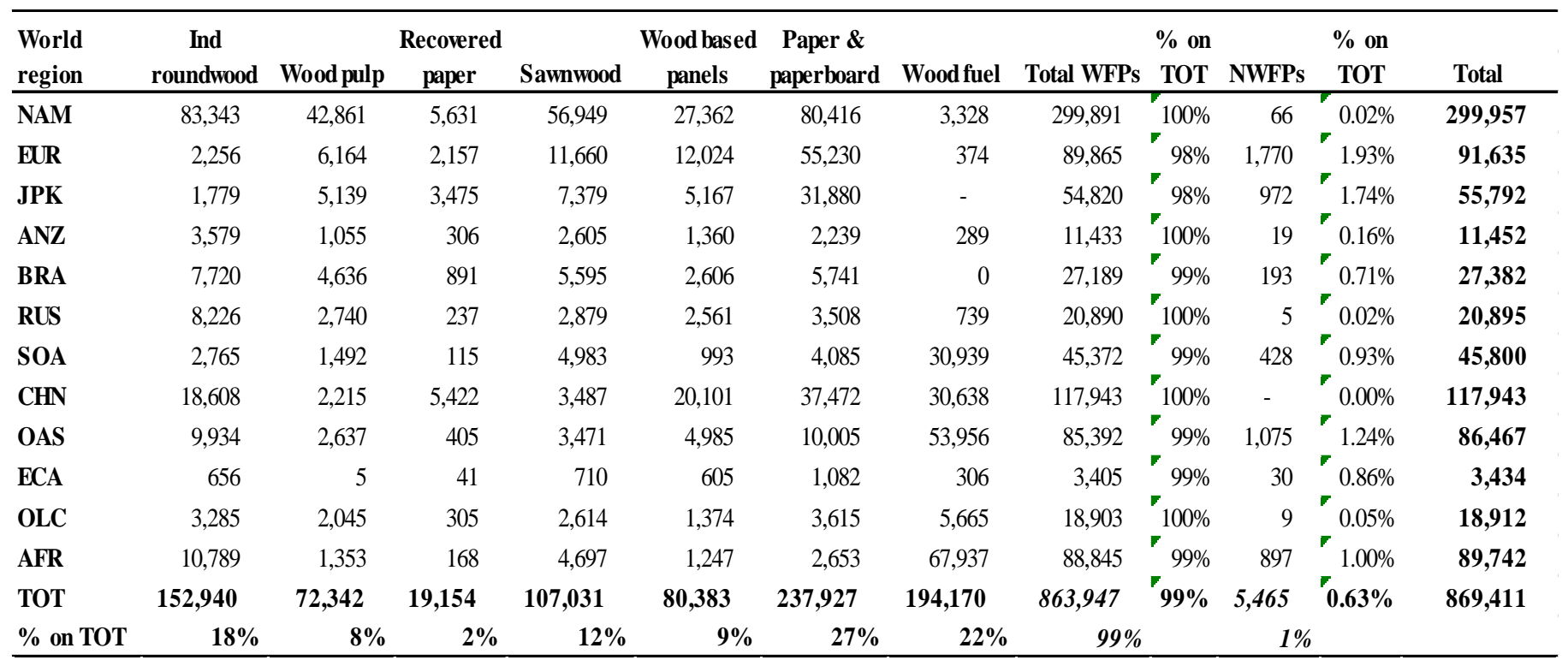


Table A4. Studies used in the meta-analysis

\begin{tabular}{|c|c|c|c|c|c|c|}
\hline N. & $\begin{array}{l}\text { Reference Study } \\
\text { (Authors and year) }\end{array}$ & Country & $\begin{array}{l}\text { World } \\
\text { region }\end{array}$ & Forest biome & $\begin{array}{l}\text { Forest } \\
\text { services }\end{array}$ & $\begin{array}{l}\text { N. } \\
\text { obs }\end{array}$ \\
\hline 1 & $\begin{array}{l}\text { Chase, L. C., D. R. Lee, W. D. } \\
\text { Schulze and D. J. Anderson (1995) }\end{array}$ & Costa Rica & OLC & $\begin{array}{l}\text { Temperate } \\
\text { coniferous }\end{array}$ & Recreation & 3 \\
\hline 2 & $\begin{array}{l}\text { Walsh, R.G., J. B. Loomis and R. A. } \\
\text { Gillman (1984) }\end{array}$ & USA & NAM & $\begin{array}{l}\text { Temperate } \\
\text { coniferous }\end{array}$ & Recreation & 4 \\
\hline 3 & $\begin{array}{l}\text { Bellu, L. G. and V. Cistulli } \\
\text { (1994) }\end{array}$ & Italy & EUR & $\begin{array}{l}\text { Temperate } \\
\text { broadleaf and } \\
\text { mixed forests }\end{array}$ & Recreation & 14 \\
\hline 4 & Campos, P. and P. Riera (1996) & Spain & EUR & Boreal forest & Recreation & 2 \\
\hline 5 & $\begin{array}{l}\text { Bateman, I.J., G.D. Garrod, } \\
\text { J.S.Brainard and A. A. Lovett (1996) }\end{array}$ & UK & EUR & Boreal forest & Recreation & 2 \\
\hline 6 & $\begin{array}{l}\text { Scarpa, R., S. M. Chilton, W. G. } \\
\text { Hutchinson, J. Buongiorno (2000) }\end{array}$ & UK & EUR & $\begin{array}{l}\text { Mediterranean } \\
\text { forest }\end{array}$ & Recreation & 8 \\
\hline 7 & $\begin{array}{l}\text { Scarpa, R., S. M. Chilton, W. G. } \\
\text { Hutchinson, J. Buongiorno (2000) }\end{array}$ & Ireland & EUR & $\begin{array}{l}\text { Temperate } \\
\text { broadleaf and } \\
\text { mixed forests }\end{array}$ & Recreation & 11 \\
\hline 8 & Bostedt, G. and L. Mattsson (2006) & Sweden & EUR & Boreal forest & Recreation & 4 \\
\hline 9 & $\begin{array}{l}\text { Zandersen, M., Termansen, M., } \\
\text { Jensen, F.S. (2005) }\end{array}$ & Denmark & EUR & $\begin{array}{l}\text { Temperate } \\
\text { broadleaf and } \\
\text { mixed forests }\end{array}$ & Recreation & 1 \\
\hline 10 & Verma, M. (2000) & India & SOA & $\begin{array}{l}\text { Tropical moist, } \\
\text { Tropical dry and } \\
\text { Montane grassl. }\end{array}$ & Recreation & 1 \\
\hline 11 & $\begin{array}{l}\text { van der Heide, C.M., van den Bergh, } \\
\text { J.C.J.M, and Nunes, P.A.L.D. (2005) }\end{array}$ & Netherlands & EUR & $\begin{array}{l}\text { Temp. Conif. and } \\
\text { Temp. Broadleaf }\end{array}$ & Recreation & 1 \\
\hline 12 & $\begin{array}{l}\text { van Beukering, P.J.H., Cesar, H.S.J., } \\
\text { Janssen, M.A. (2003) }\end{array}$ & Indonesia & OAS & Tropical moist & Recreation & 2 \\
\hline 13 & Phillips, S., Silverman, R. (2007) & USA & NAM & Temp. Conif. & $\begin{array}{l}\text { Recreation } \\
\text { /passive }\end{array}$ & 3 \\
\hline 14 & $\begin{array}{l}\text { Naidoo, R. and Adamowicz, } \\
\text { W.L.(2005) }\end{array}$ & Uganda & AFR & - & Recreation & 2 \\
\hline 15 & $\begin{array}{l}\text { Mogas, J., Riera, P. and Bennett, J. } \\
\text { (2006) }\end{array}$ & Spain & EUR & $\begin{array}{l}\text { Mediterranean } \\
\text { forest }\end{array}$ & Recreation & 2 \\
\hline 16 & $\begin{array}{l}\text { Kramer, R.A., Sharma, N., and } \\
\text { Munashinghe, M. (1995) }\end{array}$ & Madagascar & AFR & - & $\begin{array}{l}\text { Recreation } \\
\text { and } \\
\text { passive use }\end{array}$ & 2 \\
\hline 17 & $\begin{array}{l}\text { Kniivila, M., Ovaskainen, V. and } \\
\text { Saastamoinen, O. (2002) }\end{array}$ & Finland & EUR & Temp. Conif. & $\begin{array}{l}\text { Recreation } \\
\text { /passive }\end{array}$ & 2 \\
\hline 18 & $\begin{array}{l}\text { Hanley, N., Wright, R.E., } \\
\text { Adamowicz, W.L. (1998) }\end{array}$ & UK & EUR & Temp. Conif. & Recreation & 3 \\
\hline 19 & Gurluk, S. (2006) & Turkey & EUR & - & Recreation & 1 \\
\hline 20 & Emerton, L. (1999) & Kenya & AFR & $\begin{array}{l}\text { Tropical moist and } \\
\text { Montane grassl. }\end{array}$ & Recreation & 1 \\
\hline
\end{tabular}


Table A4. Studies used in the meta-analysis(con't)

\begin{tabular}{|c|c|c|c|c|c|c|}
\hline N. & $\begin{array}{l}\text { Reference Study } \\
\text { (Authors and year) }\end{array}$ & Country & $\begin{array}{l}\text { World } \\
\text { region }\end{array}$ & Forest biome & $\begin{array}{l}\text { Forest } \\
\text { services }\end{array}$ & $\begin{array}{l}\text { N. } \\
\text { obs }\end{array}$ \\
\hline 21 & $\begin{array}{l}\text { Shechter, M., Reiser, B., and Zaitsev, } \\
\text { N. (1998) }\end{array}$ & Israel & MEA & Mediterranean & Passive & 1 \\
\hline 22 & $\begin{array}{l}\text { Walsh, R.G., J. B. Loomis and R. A. } \\
\text { Gillman (1984) }\end{array}$ & USA & NAM & Temperate & Passive & 4 \\
\hline 23 & $\begin{array}{l}\text { Horton, B., Colarullo, G., Bateman, } \\
\text { I., Peres, C. (2003) }\end{array}$ & Brazil & EUR & Tropical forest & Passive & 1 \\
\hline 24 & $\begin{array}{l}\text { Kontoleon, A. and Swanson, T. } \\
\text { (2003) }\end{array}$ & China & $\mathrm{CHN}$ & $\begin{array}{l}\text { Coniferous and } \\
\text { deciduous forest }\end{array}$ & Passive & 1 \\
\hline 25 & Siikamaki, J. (2007) & Finland & EUR & Boreal & Passive & 2 \\
\hline 26 & $\begin{array}{l}\text { ERM Report to UK Forestry } \\
\text { Commission (1996) }\end{array}$ & UK & EUR & Conifer forest & Passive & 2 \\
\hline 27 & $\begin{array}{l}\text { Hanley, N., Willis, K, Powe, N, } \\
\text { Anderson, M. (2002) }\end{array}$ & UK & EUR & $\begin{array}{l}\text { Temperate, conifer } \\
\text { and broadleaved } \\
\text { woodland }\end{array}$ & Passive & 6 \\
\hline 26 & $\begin{array}{l}\text { Garrod, G.D. and Willis, K. G. } \\
\text { (1997) }\end{array}$ & UK & EUR & $\begin{array}{l}\text { Temperate, conifer } \\
\text { and broadleaved }\end{array}$ & Passive & 6 \\
\hline 27 & $\begin{array}{l}\text { Mogas, J., Riera, P. and Bennett, J. } \\
\text { (2006) }\end{array}$ & Spain & EUR & Mediterranean & Passive & 1 \\
\hline
\end{tabular}

Table A5. Projections of GDP per capita in PPP for year 2050 per world region

\begin{tabular}{llcr}
\hline World regions & Description & $\begin{array}{c}\text { GDP 2050 } \\
\text { Sbillion in PPP }\end{array}$ & $\begin{array}{c}\text { Population 2050 } \\
\text { Million }\end{array}$ \\
\hline NAM & North America & 35,700 & 565 \\
EUR & OECD Europe & 28,500 & 607 \\
JPK & OECD Asia (Japan \& Korea) & 8,200 & 177 \\
ANZ & OECD Pacific (Australia \& New Zealand) & 1,800 & 34 \\
BRA & Brasil & 3,900 & 243 \\
RUS & Russia \& Caucasus & 6,400 & 128 \\
SOA & South Asia (India+) & 26,600 & 2,321 \\
CHN & China Region & 45,000 & 1,404 \\
MEA & Middle East & 6,400 & 370 \\
OAS & Other Asia & 10,600 & 755 \\
ECA & Eastern Europe \& Central Asia & 2,200 & 118 \\
OLC & Other Latin America \& Caribbean & 6,000 & 385 \\
AFR & Africa & 14,000 & 2,014 \\
WORLD & WORLD & $\mathbf{1 9 5 , 0 0 0}$ & $\mathbf{9 , 1 2 2}$ \\
\hline
\end{tabular}

Source: Braat et al. (2008). 
Table A6. Description of World Regions

\begin{tabular}{|c|c|c|}
\hline $\begin{array}{l}\text { World } \\
\text { regions }\end{array}$ & Description & Countries included \\
\hline NAM & North America & Canada, Mexico, United States \\
\hline EUR & OECD Europe & $\begin{array}{l}\text { Albania, Andorra, Austria, Belgium, Bosnia and Herzegovina, } \\
\text { Bulgaria,Channel Islands, Croatia,Cyprus, Czech Republic, Denmark, } \\
\text { Estonia, Faeroe Islands, Finland, France, Germany, Gibraltar, Greece, Holy } \\
\text { See, Hungary, Iceland, Ireland, Isle of Man, Italy, Latvia, Liechtenstein, } \\
\text { Lithuania, Luxembourg, Macedonia, Republic of Former Yugoslav, Malta, } \\
\text { Monaco, Netherlands, Norway, Poland, Portugal, Romania, San Marino, } \\
\text { Serbia, Slovak Republic, Slovenia, Spain, Sweden, Switzerland, Turkey, } \\
\text { United Kingdom }\end{array}$ \\
\hline JPK & $\begin{array}{l}\text { OECD Asia (Japan \& } \\
\text { Korea) }\end{array}$ & Japan, Korea, Democratic People's Republic of Korea \\
\hline ANZ & $\begin{array}{l}\text { OECD Pacific } \\
\text { (Australia \& New } \\
\text { Zealand) }\end{array}$ & $\begin{array}{l}\text { American Samoa, Australia, Cook Islands, Fiji, French Polynesia, Guam, } \\
\text { Kiribati, Marshall Islands, Micronesia (Federated States of), Nauru, New } \\
\text { Caledonia, New Zealand, Niue, Northern Mariana Islands, Palau, Papua } \\
\text { New Guinea, Pitcairn, Samoa, Solomon Island, Tokelau, Tonga, Tuvalu, } \\
\text { Vanuatu, Wallis and Futuna Islands }\end{array}$ \\
\hline BRA & Brasil & Brazil \\
\hline RUS & Russia \& Caucasus & Armenia, Azerbaijan, Georgia, Russia \\
\hline SOA & South Asia (and India & $\begin{array}{l}\text { Rep. of. Afghanistan, Bangladesh, Bhutan, India, Maldives, Nepal, } \\
\text { Pakistan, Sri Lanka }\end{array}$ \\
\hline CHN & China Region & China, Hong Kong SAR, Taiwan Province of China \\
\hline OAS & Other Asia & $\begin{array}{l}\text { Mongolia, Brunei Darussalam, Cambodia, Indonesia, Lao People's } \\
\text { Democratic Republic, Malaysia, Myanmar, Philippines, Singapore, } \\
\text { Thailand, Dem. Republic of Timor-Leste, Vietnam }\end{array}$ \\
\hline ECA & $\begin{array}{l}\text { Eastern Europe \& } \\
\text { Central Asia }\end{array}$ & $\begin{array}{l}\text { Belarus, Moldova, Occupied Palestinian Territory, Tajikistan, } \\
\text { Turkmenistan, Ukraine, Uzbekistan, Kazakhstan, Kyrgyz Republic }\end{array}$ \\
\hline OLC & $\begin{array}{l}\text { Other Latin America \& } \\
\text { Caribbean }\end{array}$ & $\begin{array}{l}\text { Anguilla, Antigua and Barbuda, Aruba, Bahamas, Barbados, Bermuda, } \\
\text { British,Virgin Islands,Cayman Islands,Cuba,Dominica,Dominican } \\
\text { Republic,Grenada,Guadeloupe,Guyana,Haiti,Jamaica,Martinique,Montserr } \\
\text { at,Netherlands Antilles,Puerto Rico,South Georgia and the South Sandwich } \\
\text { Islands,St. Kitts and Nevis,St. Lucia,St. Vincent and the Grenadines,Turks } \\
\text { and Caicos Islands,United States Virgin } \\
\text { Islands,Argentina,Belize,Bolivia,Costa Rica,Chile,Colombia,Ecuador, El } \\
\text { Salvador, Falkland Islands, French Guiana, } \\
\text { Guatemala,Honduras,Nicaragua,Panama,Paraguay,Peru,Suriname,St. } \\
\text { Pierre and Miquelon,Trinidad and Tobago,Uruguay,Venezuela }\end{array}$ \\
\hline AFR & Africa & $\begin{array}{l}\text { Angola, Botswana, British Indian Ocean, Territory, Comoros, Kenya, } \\
\text { Lesotho, Madagascar, Malawi, Mauritius, Mayotte, Mali, Mauritania, } \\
\text { Morocco, Mozambique, Namibia, Niger, Réunion, Seychelles, South } \\
\text { Africa, Swazilan, Uganda, Tanzania, Zambia, Zimbabwe, Algeria, Burkina } \\
\text { Faso, Burundi, Benin, Chad, Djibouti, Egypt, Eritrea, Ethiopia, Libya, } \\
\text { Somalia, Sudan, Tunisia, Western Sahara, Cameroon, Cape Verde, Central } \\
\text { African Republic, Congo, Democratic Republic of Congo, Republic of } \\
\text { Côte d'Ivoire, Equatorial Guinea, Gabon, The Gambia, Ghana, Guinea, } \\
\text { Guinea-Bissau, Liberia, Nigeria, Rwanda, St. Helena, São Tomé and } \\
\text { Príncipe, Senegal, Sierra Leone, Togo }\end{array}$ \\
\hline
\end{tabular}




\title{
BC3 WORKING PAPER SERIES
}

\author{
Basque Centre for Climate Change (BC3), Bilbao, Spain
}

The BC3 Working Paper Series is available on the internet at the following address:

http://www.bc3research.org/lits_publications.html

http://ideas.repec.org/s/bcc/wpaper.html

BC3 Working Papers available:

2009-10

2009-11

2010-01

2010-02

2010-03

2010-04

2010-05

2010-06

2010-07

2010-08

2010-09

2010-10

2010-11

2010-12

2010-13

Elena Ojea, Ranjan Ghosh, Bharat B. Agrawal and P. K. Joshi: The Costs of Ecosystem Adaptation: Methodology and Estimates for Indian Forests

Luis M. Abadie, José M. Chamorro, Mikel Gonzáez-Eguino: Optimal Investment in Energy Efficiency under Uncertainty

Sara L. M. Trærup, Ramon Arigoni Ortiz and Anil Markandya: The Health Impacts of Climate Change: A Study of Cholera in Tanzania

Mikel González-Eguino, Ibon Galarraga and Alberto Ansuategi: Carbon leakage and the Future of Old Industrial Regions after Copenhagen

Roger Fouquet: Divergences in the Long Run Trends in the Price of Energy and of Energy Services

Giacomo Giannoccaro and Julia Martin-Ortega: Environmental Concerns in Water Pricing Policy: an Application of Data Envelopment Analysis (DEA)

Roger Fouquet: The Slow Search for Solutions: Lessons from Historical Energy Transitions by Sector and Service

Ibon Galarraga, Mikel González-Eguino and Anil Markandya: Evaluating the Role of Energy Efficiency Labels: the Case of Dish Washers

Luis M. Abadie, Mikel González-Eguino and José M. Chamorro: Optimal Abandonment of Coal-Fired Stations in the EU

Dirk Rübbelke and Stefan Vögele: Impacts of Climate Change on European Critical Infrastructures: The Case of the Power Sector

Roger Fouquet: The Sustainability of 'Sustainable' Energy Use: Historical Evidence on the Relationship between Economic Growth and Renewable Energy

Karen Pittel and Dirk Rübbelke: Energy Supply and the Sustainability of Endogenous Growth

Ramon Arigoni Ortiz, Alexander Golub, Oleg Lugovoy, Anil Markandya and James Wang: The DICER Model: MethodologicalIissues and Iinitial Results.

Elena Ojea, Julia Martin-Ortega and Aline Chiabai: Classifying Ecosystem Services for Economic Valuation: the Case of Forest Water Services

Aline Chiabai, Chiara Travisi, Anil Markandya, Helen Ding, and Paulo Nunes: Economic Assessment of Forest Ecosystem Services Losses: Cost of Policy Inaction 